University of Tennessee Health Science Center

UTHSC Digital Commons

\title{
Impact of Cost Sharing Levels on Adherence to Controller Drugs and Consequent Outcomes among Asthma Patients
}

Varun Vaidya

University of Tennessee Health Science Center

Follow this and additional works at: https://dc.uthsc.edu/dissertations

Part of the Health and Medical Administration Commons

\section{Recommended Citation}

Vaidya, Varun, "Impact of Cost Sharing Levels on Adherence to Controller Drugs and Consequent Outcomes among Asthma Patients" (2009). Theses and Dissertations (ETD). Paper 277. http://dx.doi.org/ 10.21007/etd.cghs.2009.0332.

This Dissertation is brought to you for free and open access by the College of Graduate Health Sciences at UTHSC Digital Commons. It has been accepted for inclusion in Theses and Dissertations (ETD) by an authorized administrator of UTHSC Digital Commons. For more information, please contact jwelch30@uthsc.edu. 


\title{
Impact of Cost Sharing Levels on Adherence to Controller Drugs and Consequent Outcomes among Asthma Patients
}

\begin{abstract}
Prescription drug cost sharing is an effective tool to reduce the excessive drug consumption. However, many times it could have a negative impact on the drug utilization especially in case of chronic conditions. Chronic conditions such as asthma require appropriate utilization of controller medication to keep the inflammation and symptoms under control. Literature on asthma drug utilization has consistently reported underuse of controller drugs among asthma patients. The present study attempted to investigate the impact of prescription drug cost sharing levels on the controller adherence among the privately insured asthma population with moderate persistent asthma. The study also analyzed the relationship between adherence and asthma related health services utilization outcomes.

A retrospective analysis using the MarketScan administrative claims database was conducted for the years 2000 and 2001. Asthma patients that were stepped up to dual controller therapy in the study period and had no diagnosis for COPD or other respiratory conditions were included in the study. Study participants were also required to be in the age range of 5-65 and continuously enrolled in the health plan for the entire study period. Multivariate regression analysis using SAS 9.1 was performed to analyze the relationship between cost sharing levels and controller adherence. Linear probabilistic models were built to analyze the relationship between adherence and asthma related health services utilization.

A total of 1447 patients met the study criteria. The overall association between cost sharing and adherence was significantly negative. The drop in adherence to Inhaled Corticosteroids (ICS) with respect to cost sharing was greater after the patients were stepped to the dual controller therapy. Comparison of subgroups that used ICS+ LABA and ICS + LTRA revealed that the subjects ICS+LTRA subgroup are slightly more sensitive to the out of pocket costs. The analysis of adherence and health services utilization showed mixed results with reduction in ER visits but no association of hospital stay and SAB use.

Cost sharing levels had a negative impact on utilization of controller drugs. In terms of ICS adherence pre and post index periods, it can be concluded that the increased cost burden affected significantly even though the need to be adherent was increased. Based on the sub group analysis in the post-index period between the two add-on options, ICS + LTRA subgroup was more sensitive to the price changes. Adherence to controller regimen had a negative impact on ER visits however the data did not provide evidence in case of hospitalizations and SAB use.
\end{abstract}

Document Type

Dissertation

Degree Name

Doctor of Philosophy (PhD)

Program

Health Outcomes and Policy Research

Research Advisor

Song Hee Hong, Ph.D. 


\section{Keywords}

Adherence, Asthma, Controllers, Cost-sharing, Outcomes

\section{Subject Categories}

Health and Medical Administration I Medicine and Health Sciences 


\title{
IMPACT OF COST SHARING LEVELS ON ADHERENCE TO CONTROLLER DRUGS AND CONSEQUENT OUTCOMES AMONG ASTHMA PATIENTS
}

\begin{abstract}
A Dissertation Presented for The Graduate Studies Council The University of Tennessee

Health Science Center
\end{abstract}

In Partial Fulfillment

Of the Requirements for the Degree

Doctor of Philosophy

From The University of Tennessee

By

Varun Vaidya

May 2009 
Copyright (C) 2009 by Varun Vaidya All rights reserved 


\section{Dedication}

This dissertation is dedicated to my wife Renuka and my parents,

Dr. Anil Vaidya and Mrs. Anjali Vaidya. 


\section{Acknowledgements}

I would like to thank my major professor, Dr. Song Hee Hong for his support and help throughout this dissertation process.

I would also like to thank my dissertations committee members; Dr. Raoul Arreola, Dr. Dick Gourley, Dr. Jim Wan and Dr. Shelley White-Means for providing me excellent feedback and also for their continuous encouragement. Without them this dissertation could not have been possible.

I would like to thank Thomason Reuters for providing the MarketScan administrative claims database.

Finally I would like to thank all my friends and colleagues at UT for always being there for me. 


\begin{abstract}
Prescription drug cost sharing is an effective tool to reduce the excessive drug consumption. However, many times it could have a negative impact on the drug utilization especially in case of chronic conditions. Chronic conditions such as asthma require appropriate utilization of controller medication to keep the inflammation and symptoms under control. Literature on asthma drug utilization has consistently reported underuse of controller drugs among asthma patients. The present study attempted to investigate the impact of prescription drug cost sharing levels on the controller adherence among the privately insured asthma population with moderate persistent asthma. The study also analyzed the relationship between adherence and asthma related health services utilization outcomes.
\end{abstract}

A retrospective analysis using the MarketScan administrative claims database was conducted for the years 2000 and 2001. Asthma patients that were stepped up to dual controller therapy in the study period and had no diagnosis for COPD or other respiratory conditions were included in the study. Study participants were also required to be in the age range of 5-65 and continuously enrolled in the health plan for the entire study period. Multivariate regression analysis using SAS 9.1 was performed to analyze the relationship between cost sharing levels and controller adherence. Linear probabilistic models were built to analyze the relationship between adherence and asthma related health services utilization.

A total of 1447 patients met the study criteria. The overall association between cost sharing and adherence was significantly negative. The drop in adherence to Inhaled Corticosteroids (ICS) with respect to cost sharing was greater after the patients were stepped to the dual controller therapy. Comparison of subgroups that used ICS+ LABA and ICS + LTRA revealed that the subjects ICS+LTRA subgroup are slightly more sensitive to the out of pocket costs. The analysis of adherence and health services utilization showed mixed results with reduction in ER visits but no association of hospital stay and SAB use.

Cost sharing levels had a negative impact on utilization of controller drugs. In terms of ICS adherence pre and post index periods, it can be concluded that the increased cost burden affected significantly even though the need to be adherent was increased. Based on the sub group analysis in the post-index period between the two add-on options, ICS + LTRA subgroup was more sensitive to the price changes. Adherence to controller regimen had a negative impact on ER visits however the data did not provide evidence in case of hospitalizations and SAB use. 


\section{Table of Contents}

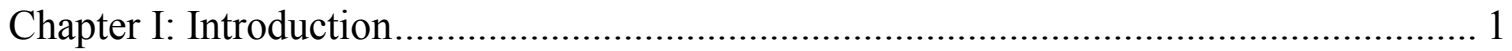

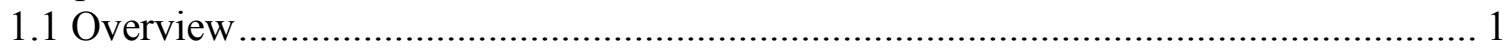

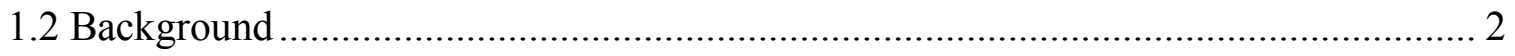

1.2.1 Poor adherence to controller drugs .......................................................... 2

1.2.2 Relationship between out of pocket cost and adherence ................................. 3

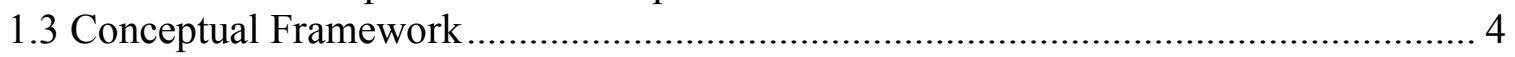

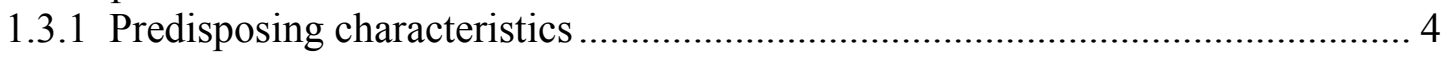

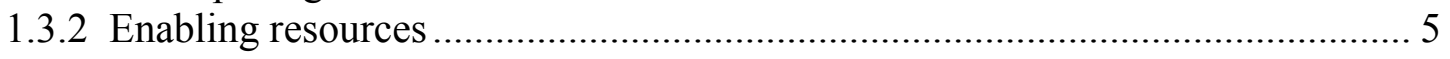

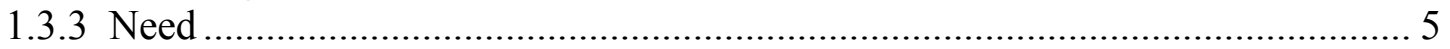

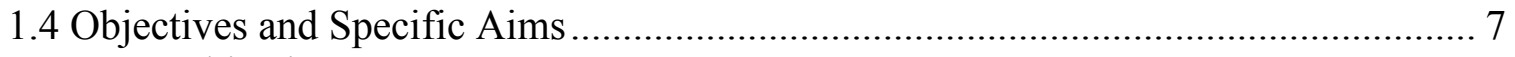

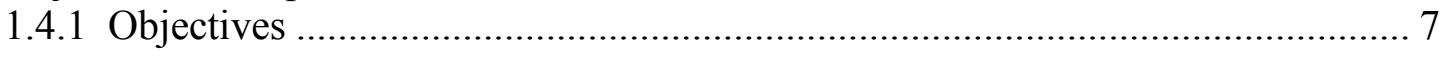

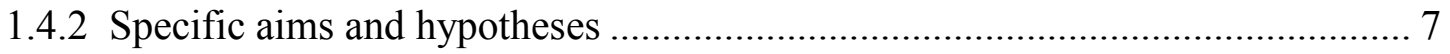

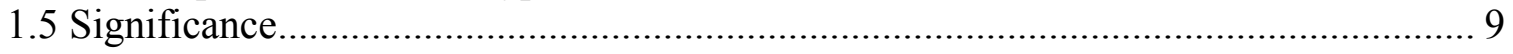

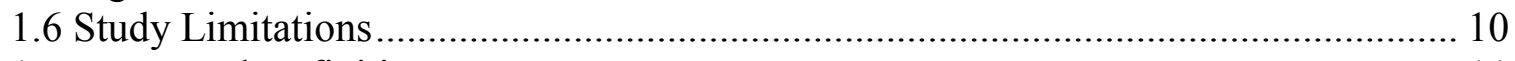

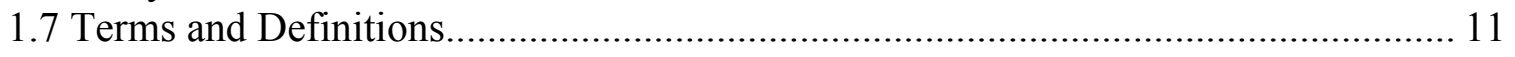

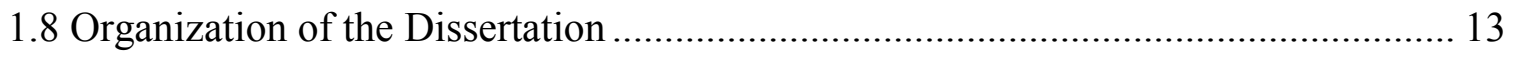

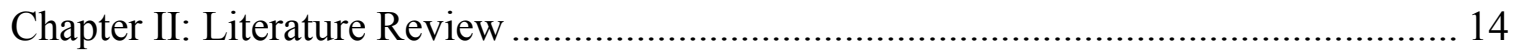

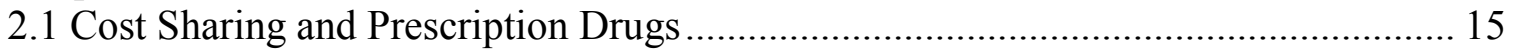

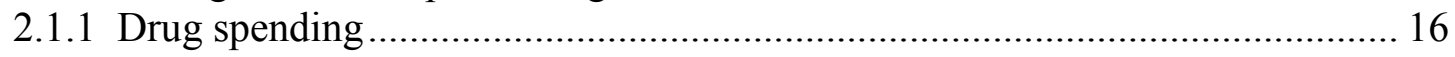

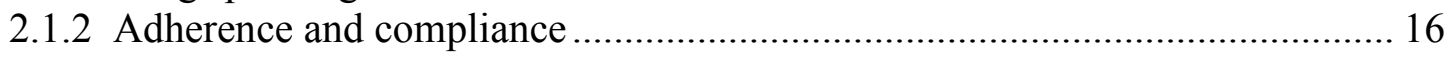

2.1.3 Asthma related healthcare resources utilization outcomes ............................ 17

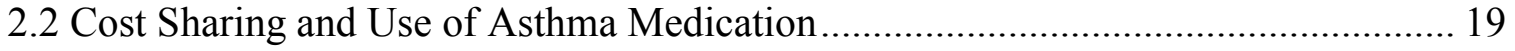

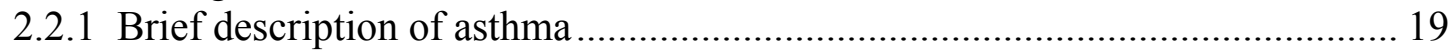

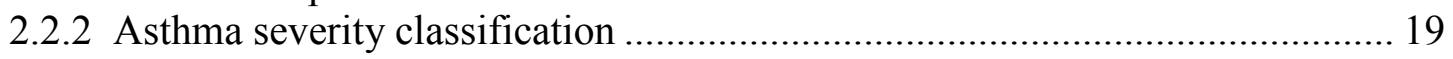

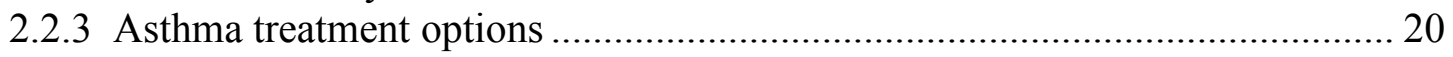

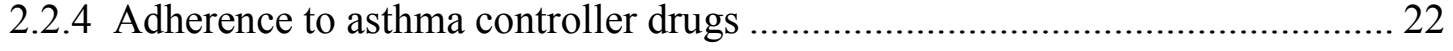

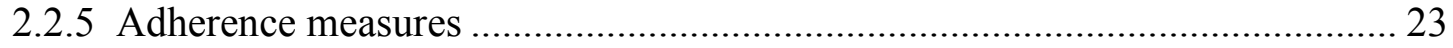

2.2.6 Cost sharing and controller drugs utilization ............................................ 25

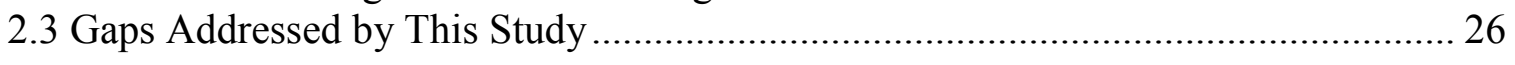

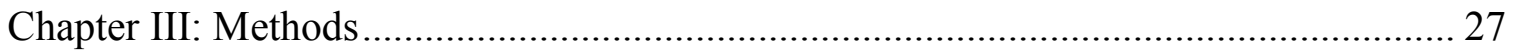

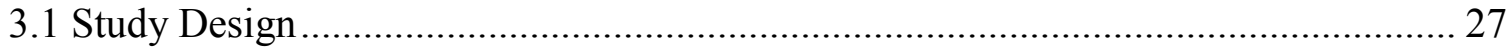

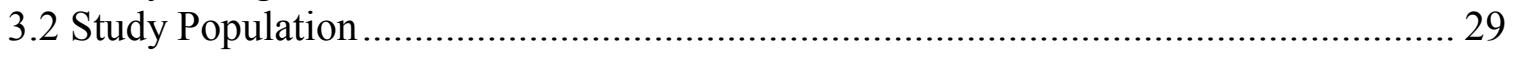

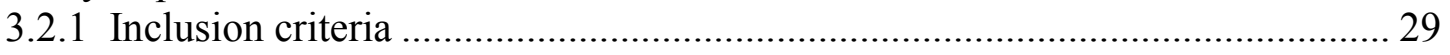

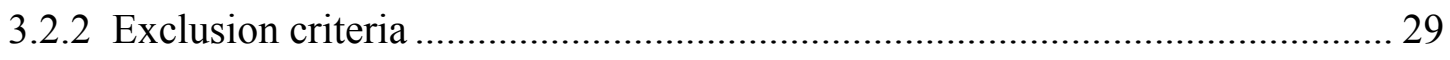

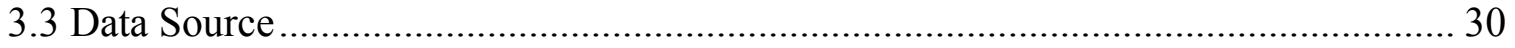

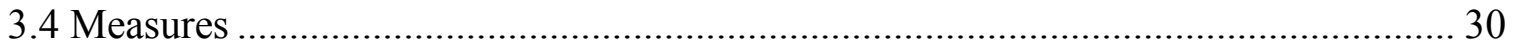

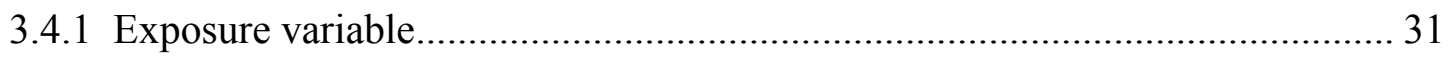

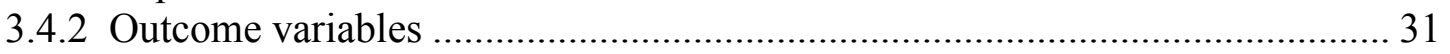

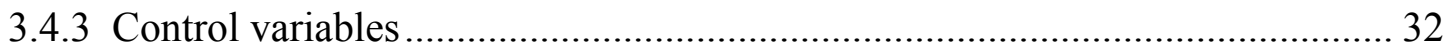

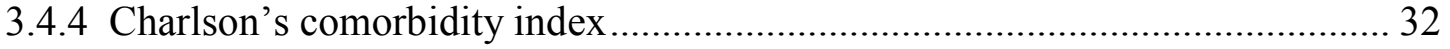




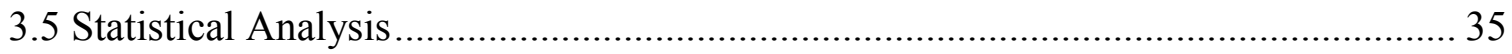

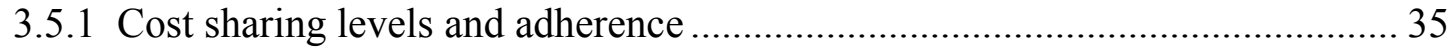

3.5.2 Adherence and resource utilization outcomes ................................................ 36

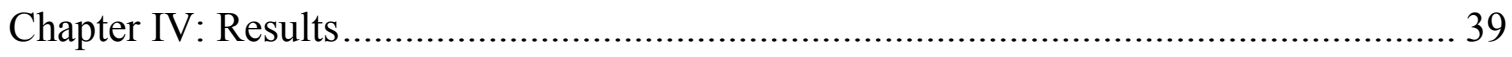

4.1 Sample Selection and Sample Characteristics .................................................. 39

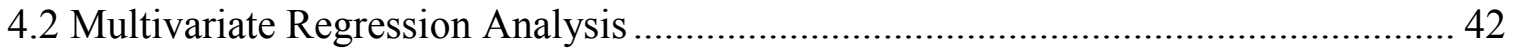

4.3 Comparison of Regression Co-efficient between ICS+LABA and ICS+LTRA ....... 45

4.4 Adherence and Healthcare Resources Utilization................................................. 45

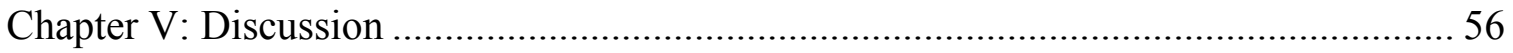

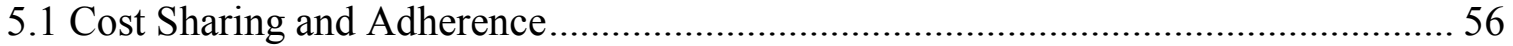

5.2 Health Services Utilization Outcomes .................................................................... 58

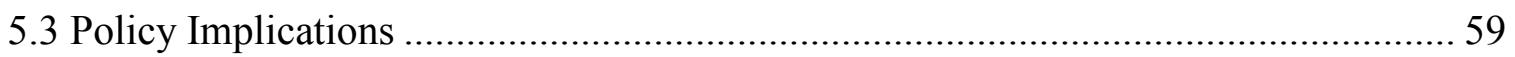

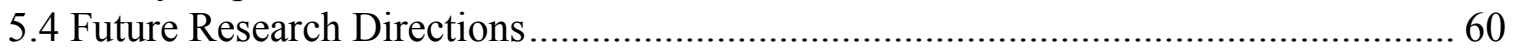

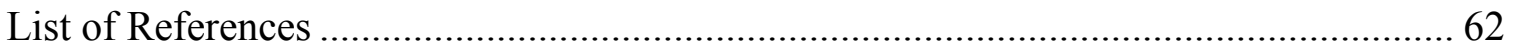

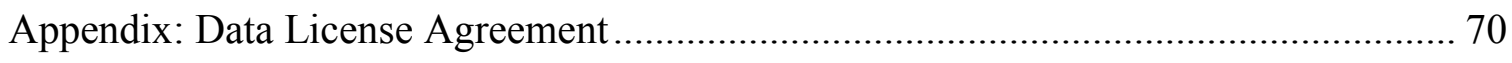

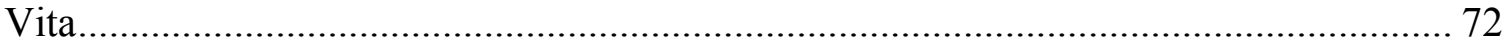




\section{List of Tables}

Table 1 Asthma severity definition according to NHLBI guidelines ......................... 21

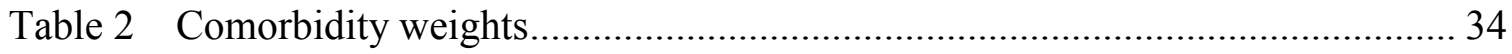

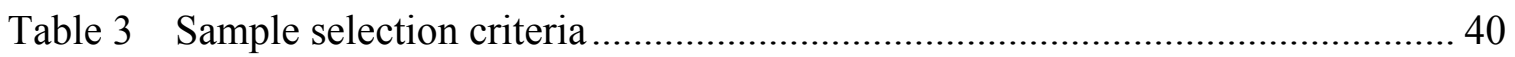

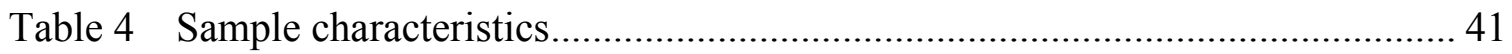

Table 5 Multivariate regression: association between cost sharing and combined controller (ICS+LABA/ LTRA) adherence .............................................. 43

Table 6 Multivariate regression: association between cost sharing and steroid adherence in the pre-index and post-index period.......................................... 44

Table 7 Pre-index characteristics for ICS+LABA and ICS+LTRA cohorts ................. 46

Table 8 Multivariate regression: association between cost sharing and

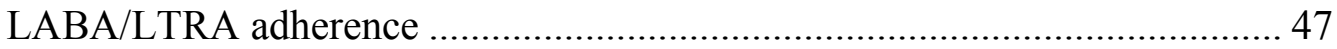

Table 9 Unadjusted healthcare utilization for the post-index follow up period ........... 48

Table 10 Multivariate two stage regression: association between controller adherence and number of ER visits

Table 11 Multivariate two stage regression: association between controller adherence and ER visits among ICS+LABA and ICS+LTRA cohorts....

Table 12 Multivariate two stage regression: association between controller adherence and number of hospital days

Table 13 Multivariate two stage regression: association between controller adherence and hospital stay among ICS+LABA and ICS+LTRA cohorts ...... 53

Table 14 Multivariate two stage regression: association between controller adherence and SAB refills

Table 15 Multivariate two stage regression: association between controller adherence and SAB refills among ICS+LABA and ICS+LTRA cohorts 


\section{List of Abbreviations}

COMPACT

COPD

CR

DBR

ER

GOAL

HMO

ICD-9-CM

ICS

LABA

LTRA

MPR

MPRm

MRA

NAEPP

NCEH

NHLBI

NIAID

PDC

RAND HIE

RCR

SAB

SRM

TNEOR
Clinical Outcomes with Montelukast as a Partner Agent to

Corticosteroid Therapy

Chronic Obstructive Pulmonary Disease

Compliance Rate

Dates Between Rate

Emergency Room

Gaining Optimal Asthma controL

Health Maintenance Organization

International Classification of Diseases, 9th Revision, Clinical

Modification

Inhaled Corticosteroids

Long-Acting Beta-2 Agonists

Leukotrine Receptor Antagonist

Medication Possession Ratio

Medication Possession Ratio, modified

Medication Refill Adherence

National Asthma Education and Prevention Program

National Center for Environmental Health

National Heart, Lung, and Blood Institute

National Institute of Allergy and Infectious Diseases

Proportion of Days Covered

Rand Health Insurance Experiment

Refill Compliance Rate

Short Acting Bronchodilators

Self Regulatory Model

The Epidemiology and Natural History of Asthma Outcomes and Treatment Regimen 


\section{Chapter I: Introduction}

\section{$\underline{1.1 \text { Overview }}$}

The concept of cost sharing in healthcare has been around for years. Work published by health economist Kenneth Arrow demonstrated the phenomenon of moral hazard among those with health insurance, ${ }^{1}$ which in turn stimulated a need to contain the moral hazard. Moral hazard is defined as the change in behavior when people are insulated from risk. ${ }^{2}$ It happens when an individual does not carry the responsibility of their actions, has a tendency to act less carefully than he/she otherwise would. In a response to counter the moral hazard, insurance companies started using several cost sharing techniques such as annual deductibles and co-payments to control the overall healthcare expenditures. The success of cost sharing techniques in controlling the moral hazard is well documented by previous studies. ${ }^{3-5}$ However, while the cost sharing strategy is observed as an excellent tool to counter the moral hazard and unnecessary drug utilization, it has also been documented that the higher cost sharing levels may lead

to under use of heath care. ${ }^{6}$ Hence to maintain an optimum balance between cost sharing and appropriate health care consumption, it is important to study the effect of cost sharing on patient adherence to the treatment.

Even though prescription drugs are part of health care services, in a typical health insurance coverage policy they are separated from other health services and form a supplementary addition to a health coverage policy. However, as the prices for prescription drugs started rising, insurance companies have introduced cost sharing policies in the supplementary drug policies as well. The main purpose of cost sharing again was to discourage patients from consuming unnecessary care. On the other hand if the patients have to pay too much out of pocket cost they may be discouraged from utilizing necessary care. Therefore achieving the correct balance where patients are encouraged to use needed care but at the same time are discouraged to use unneeded care is critical. This brings us to an important issue where we need to determine if cost sharing levels imposed in the drug plans are adversely affecting utilization of necessary drugs especially in cases of chronic conditions where poor adherence may lead to worse outcomes.

In this study, the investigator sought to determine the impact of cost sharing on adherence to asthma controller drugs among asthma patients from age five and above. The focus was on the patients with asthma severity at a moderate persistent level which is characterized by use of more than one controller medication. In case of moderate persistent asthma, the patients need more medical attention as their asthma is not controlled by one controller medication alone. Poor adherence to the controller 
medication has more severe implications in case of these asthma patients. Therefore compared to the asthma patients with mild asthma these patients are in greater need of being adherent to the prescribed regimen for asthma treatment.

\subsection{Background}

Asthma is a chronic respiratory condition and if not managed effectively it may result in hospitalizations, emergency room visits, and reduced quality of life. ${ }^{7}$ Besides avoiding the things that trigger an asthma attack, the most effective treatment for asthma is use of medications. ${ }^{8}$ There are mainly two types of medications available for asthma treatment, short acting relievers and long acting controllers. The current National Heart, Lung, and Blood Institute (NHLBI) guidelines ${ }^{8}$ for the treatment of persistent asthma advocate use of long-term control medications (to be taken daily on a long-term basis) to achieve and maintain adequate control. For asthma patients suffering from daily symptoms and requiring use of Short Acting Bronchodilators ( $\mathrm{SAB}$ ) on an everyday basis along with exacerbations affecting activity greater than two times per week, guidelines recommend use of dual controller therapy. ${ }^{9}$ Dual controller therapy is a combination of Inhaled Corticosteroids (ICS) along with another controller drug such as Long-acting inhaled 3 2-agonist (LABA) or Leukotrine Receptor Antagonist (LTRA).

\subsubsection{Poor adherence to controller drugs}

Despite the recommendations from national asthma guidelines, the controller drug underutilization and overuse of the quick relief medications still persists. ${ }^{10-12}$ The Epidemiology and Natural History of Asthma Outcomes and Treatment Regimens (TENOR) study reported that the controller drug utilization is less than optimum among many asthma patients who are at high risk of morbidity and mortality. ${ }^{11}$ The asthma medication treatment emphasis is shifting towards more use of the controller drugs that are effective in preventing asthma exacerbations than the relievers that play no role in controlling the asthma itself. Poor adherence to the controller drugs is also considered a major contributor towards poor control and morbidity associated with asthma. If asthma is not controlled adequately then it can affect the severity levels of the disease resulting in more severe asthma condition.

For asthma patients having moderate persistent or higher severity, NHLBI guidelines ${ }^{9}$ emphasize even greater focus on use of controller drugs. Patients are recommended to initiate a step up therapy consisting of two different controller drugs. However, studies have reported lower rate of adherence even among these patients that 
needs more attention. Stern et al reported an average MPR (Medication Possession Ratio) of 0.36 among the asthma population taking more than one controller medication. ${ }^{12}$

Considering that the value for MPR ranges from 0 to $1,0.36$ indicates a very low adherence. Unfortunately there is no cure for asthma and the only means to treat asthma besides avoiding the substances that trigger asthma attacks is to use medications. Poor adherence to controller medications even among asthma patients that are in more need to control their conditions, highlights the need to investigate factors behind the low adherence and possible solutions to improve the adherence.

\subsubsection{Relationship between out of pocket cost and adherence}

As mentioned earlier out of pocket cost has an inverse relationship with adherence to the medications across a wide range of chronic conditions. Several studies ${ }^{6,13-15}$ have documented significant rates of medication underuse as a result of the burden of out of pocket costs in the United States. In the case of chronic conditions such as asthma, medication adherence is essential to control the disease. However, if out of pocket costs are unaffordable to the patients, then it is likely that they will skip the medication. Moreover, majority of the controller drugs (such as widely used ICS) do not produce any symptomatic relief making them more vulnerable to poor adherence rates. A study done by Byer et a $1^{16}$ using Leventhal's Self Regulatory Model (SRM) as a theoretical framework found that the symptoms associated with the illness play a key role in adherence to then medication among asthma patients. Medications such as asthma controllers have to be taken for a very long time without being able to experience immediate symptomatic relief and therefore higher costs associated with such medications can discourage the patients from utilizing the drugs properly.

As mentioned before, lower adherence to controller drugs can lead to worsening the asthma symptoms which ultimately can result in a stepped up therapy with dual controller medications. ${ }^{17}$ According to national guidelines patients are stepped up from one controller medication to two medications when asthma is not controlled enough by one controller alone. ${ }^{9}$ To achieve better control over the condition, patients need more than one controller drugs. Severity indicators such as inflammation levels and lung function are worse among such patients and therefore they are required to be more adherent to the treatment regimen than the patients having their asthma severity at mild level.

Once the patients are stepped up to the dual controller therapy they have to pay for two controller drugs making the overall treatment less affordable and more 
burdensome. Compared to the reliever drugs, controller drugs are more expensive and when searched for the various drug plans offered in Tennessee were found to be placed in the second or third tier of the pharmacy benefit plan. According to drugstore.com (an online retailer of prescription drugs), the cost of Azmacort (asthma controller drug) inhaler was found to be $\$ 131.24$ whereas Alupent (Short Acting Bronchodilator) $0.65 \mathrm{mg} /$ act Aerosol 14gm Inhaler was found to be for $\$ 37.87$.

\section{$\underline{1.3 \text { Conceptual Framework }}$}

As improved outcomes are expected through appropriate adherence to them, first it is necessary to establish a relationship between the health insurance status and asthma drug utilization, before analyzing the economical and health outcomes. However the individual healthcare utilization cannot be explained as a function of coinsurance level alone. It is characterized by a person's individual and social determinants. In order to measure the isolated effects of health insurance status on the drug utilization, it is necessary to identify and control for all the individual and social characteristics that are likely to influence one's health care utilization. To control the factors influencing one's prescription drug utilization, the conceptual framework of this study incorporated the health utilization model developed by R.M Anderson ${ }^{15}$

This model has been cited by several studies ${ }^{18-20}$ focusing on health services utilization among asthma patients. Initially this model was developed to focus on 'family' as the unit of analysis. Later on it was modified to shift the focus to the 'individual' as the unit of analysis to address the health services utilization more appropriately. ${ }^{21}$ This model captures health services utilization behavior as a function of their 1) predisposition to use; 2) enabling resources to use; and 3) need to use the health services.

\subsubsection{Predisposing characteristics}

Every individual has a different propensity to use health care resources. ${ }^{21}$ Existence of different propensities is a result of the diversity in characteristics of every individual. Such characteristics are broadly categorized into demographic, social structural and attitudinal-belief variables under the predisposing factors to use the health care services. Demographics such as age and sex are examples of demographic variables that are closely related to health of an individual. The social structure variables refer to the status of the individual in his society. Depending upon these characteristics use of health care services varies among different patient populations. Although predisposing variables are not directly associated with the patient's healthcare utilization patterns, they 
create differences in inclinations towards use of health care services. As a result, the different healthcare utilization patterns are observed with different predisposing characteristics. For example, people in different age groups have different types of illnesses and severities and therefore are likely to have different healthcare use patterns. In case of asthma predisposing factor such as age is important because the evidence indicates that aging has an adverse effect on lung elastin fibers which has been correlated to the severity of the disease. ${ }^{22}$

\subsubsection{Enabling resources}

Being predisposed to utilization alone may not result in actual utilization of the health services. Along with predisposition to use, adequate resources are required to be available to translate the predisposition into actual use. There are two major categories of enabling resources, personal/ family and community. Family/personal income is an example of variable in personal/family category affecting individual utilization of health services. Variables such as, availability of health care facilities and access to them fall under the community category of enabling resources. Other community variables such as rural or urban nature of the community also influence use of health services because they sometimes are associated with the way how the medicine should be practices. Enabling resources play a key role by providing necessary means to obtain the health care services by the patients.

\subsubsection{Need}

Other than the predisposition to use and availability of enabling resources, presence of an illness and degree of it is also important in predicting health services use. It is important for an individual or a family to perceive the illness or probability of its occurrence to seek any kind of health care services. Being predisposed and availability of necessary means are not sufficient to use healthcare services if there is no need for it perceived by the individual or the family. Need characteristics explain the behavior of those patients who are predisposed to the health care use and also have means to obtain it but are still not consuming it. Illness level represents the most immediate cause to use any health services. Examples of perceived illness include self reported general state of health such as excellent, good, poor etc.

The final conceptual framework for this study (Figure 1) was created by extending the Anderson's health utilization model further to include the asthma related healthcare resources utilization outcomes. 


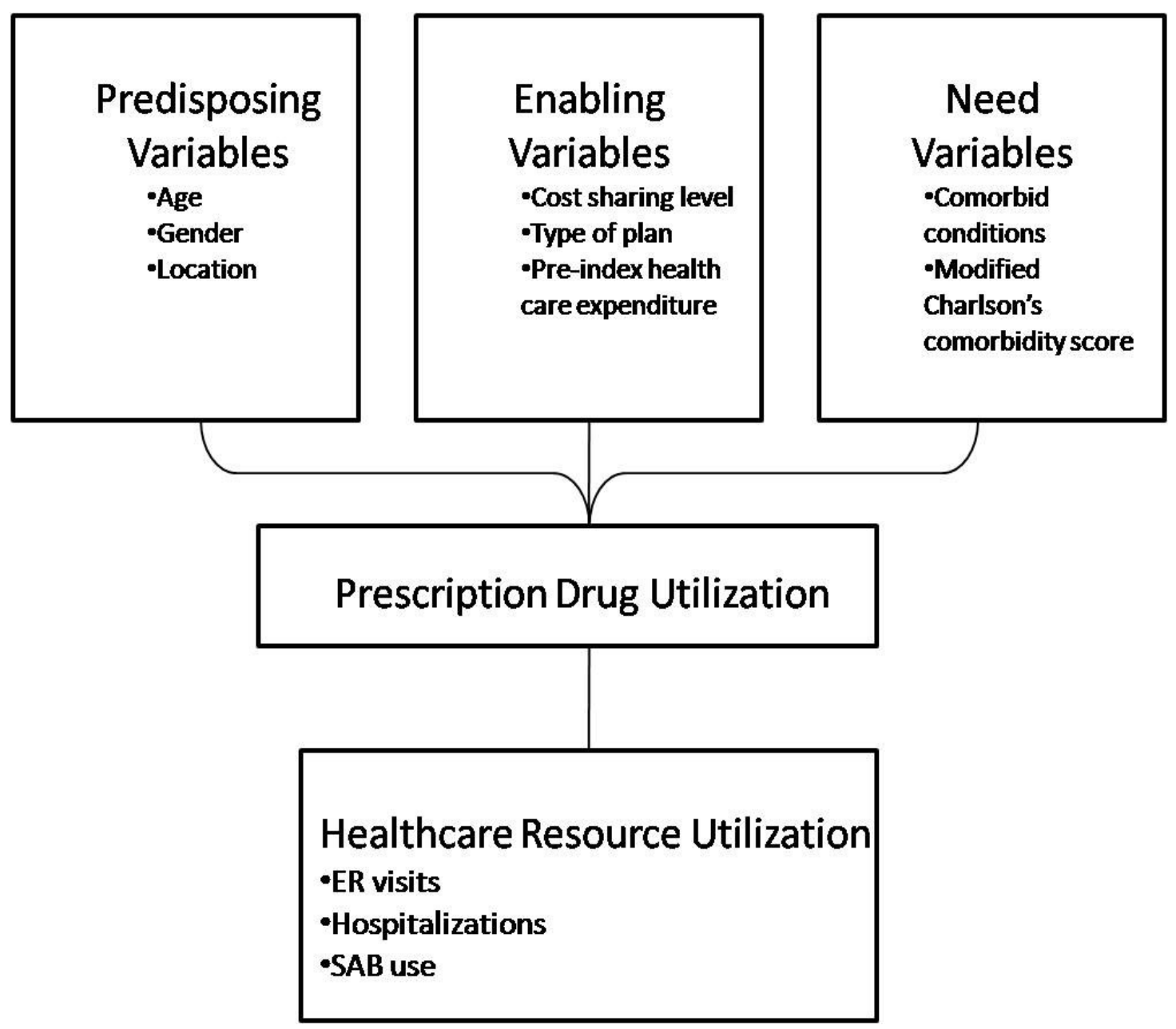

Figure 1 Conceptual framework based on Anderson's healthcare utilization model

Source: Modified with permission Andersen RM. Revisiting the behavioral model and access to medical care: does it matter? J Health Soc Behav 1995 March;36(1):1-10. ${ }^{18}$ Legend: ER = Emergency Room.

$\mathrm{SAB}=$ Short Acting Bronchodilators. 
Once the link between cost sharing and medication utilization is established it is important to analyze effects of adherence levels on healthcare resources utilization outcomes to fully understand the impact of cost related poor adherence. Cost related poor adherence has been documented to be associated with poor health outcomes in case of chronic conditions. ${ }^{23}$ Extending the Anderson's model to include healthcare services utilization outcomes, helped to understand if patients who are struggling to be adherent to the controller regimen are suffering from poor healthcare resources utilization outcomes as well. Healthcare services utilization outcomes associated with asthma such as ER visit, hospitalization and use of SAB were included. This conceptual framework helped us to determine the variables to be measured and also the statistical relationships required to be studied.

\subsection{Objectives and Specific Aims}

\subsubsection{Objectives}

The main objectives of this study were to examine the impact of cost sharing among asthma population suffering from moderate persistent asthma (age group 4-65) on adherence to asthma controller medications and also to analyze patient level outcomes such as ER visits, hospitalization and use of SAB. The study had the following specific aims:

\subsubsection{Specific aims and hypotheses}

1. To determine the distribution of asthmatic population diagnosed with moderate persistent asthma (stepped up from Inhaled corticosteroids alone to Inhaled Corticosteroids + Long-acting inhaled $\beta_{2}$-agonist (ICS + LABA) and Inhaled Corticosteroids + Leukotrine Receptor Antagonist (ICS + LTRA))

2. To quantify the change in Medication Possession Ratio (adherence measure) of controller medication combination (ICS+LABA/LTRA) with respect to increase in cost sharing level after controlling for other covariates. Hypothesis: As the increased cost sharing levels are known to have inverse relationship with the utilization of health care services, it is hypothesized that the MPR for the asthma patients will go down as the cost sharing levels go up. The null and alternative hypotheses are, $\mathbf{H}_{\mathbf{0}}$ : MPR does not change with change in cost sharing levels 
$\mathbf{H}_{1}$ : MPR changes with change in cost sharing levels

2a. To compare changes in Medication Possession Ratio (adherence measure) with respect to increase in cost sharing level between patients stepped up with ICS+LABA and patients stepped up with ICS+LTRA combination

Hypothesis: As the LABA and LTRA have different mechanism of actions it is hypothesized that adherence levels will be with respect to the cost sharing levels will be significantly different. The null and alternative hypotheses are,

$\mathbf{H}_{\mathbf{0}}$ : There is no change in MPR with respect to cost sharing levels among ICS+LABA and ICS+LTRA users.

$\mathbf{H}_{1}$ : The MPR with respect to cost sharing levels changes among ICS+LABA and ICS+LTRA users.

$2 \mathrm{~b}$. To analyze change in medication possession ratio with respect to increase in cost sharing levels of ICS only before and after the patients were stepped up to the dual controller therapy. Hypothesis: As the increased cost sharing levels are known to have inverse relationship with the utilization of health care services, it is hypothesized that the MPR for the asthma patients will go down as the cost sharing levels go up. The null and alternative hypotheses are, $\mathbf{H}_{\mathbf{0}}$ : There is no change in ICS MPR with respect to cost sharing levels before and after getting steeped up to dual controller therapy. $\mathbf{H}_{\mathbf{1}}$ : The ICS MPR with respect to cost sharing levels changes before and after getting stepped up to dual controller therapy.

3. To examine the association between adherence to asthma controller therapy and asthma related health services utilization (SAB utilization, ER visits, Hospitalization) among the moderate persistent asthma patients.

Hypothesis: The controller therapy has been reported to be effective for the asthma patients in controlling the conditions and therefore it is hypothesized that the adherence levels will result in decreasing the asthma related health services utilization such as SAB use, ER visits, Hospitalization. The null and alternative hypotheses are,

$\mathbf{H}_{\mathbf{0}}$ : Adherence to controller drugs has no impact on asthma related health services utilization.

$\mathbf{H}_{1}$ : Adherence to controller drugs has a negative impact on asthma related health services utilization. 


\section{$\underline{1.5 \text { Significance }}$}

The prevalence of asthma along with the severity and frequency of exacerbations appears to be increasing worldwide. ${ }^{24}$ In addition the lower rates of controller adherence are contributing to worsening the situation. Despite the recommendations from guidelines to use more than one controller drug, the studies have reported lower levels of controller adherence even among asthma patients having moderate persistent asthma. So far the factors reported in the literature to be associated with lower adherence to controller medications are lack of medication efficacy (real or perceived), taste of medication, multiple dosing intervals, long stressful demanding regimens and incorrect prescription given by clinicians. ${ }^{12}$

At the same time to control the increase in prescription drug spending many plans are increasing the levels of copayment across all tiers leading to an increased cost burden on patients. ${ }^{25}$ This increase in copayment level brings up two important issues needed to be addressed: 1) Does the increase in cost sharing level affect the utilization of appropriate prescription drugs; and 2) To what degree the health outcomes associated with the utilization are affected. There is a significant body of research showing the association of higher cost sharing and lower adherence levels, but impact of cost sharing on adherence in case of asthma patients has not been explored thoroughly with only a few studies available. As explained before, among asthma patients poor adherence levels of controller drugs are reported and since the role played by increasing cost sharing levels in the poor adherence has not been explored thoroughly it is important to produce more studies in this area. In this study the role played by cost sharing levels in adherence to controller drugs among the asthma patients having moderate persistent asthma was investigated. Investigating impact of cost sharing on adherence levels can help to understand the importance of cost burden as a barrier to access controller drugs.

Additionally, the study also compared patient's adherence levels with respect to the cost sharing levels before they were diagnosed with moderate persistent asthma (stepped up to dual controller therapy). This helped to determine if there is any change in the sensitivity to the cost sharing levels after they were diagnosed with moderate persistent asthma. According to the guidelines patients are stepped up to the dual controller therapy when the asthma symptoms are not controlled adequately by using ICS alone. When the patients are stepped up to the dual controller therapy, the need to be adherent to the regimen is even greater. But on the other hand the cost burden is also increased because of the increased number of controller drugs. Therefore, studying the association of cost sharing with the adherence before and after the patients are stepped up provided a more comprehensive picture of the impact of cost sharing on adherence. 


\subsection{Study Limitations}

The analysis was carried out using medical and pharmacy claims data bases to examine the association of cost sharing and adherence to the controller regimen and relationship of adherence with the health outcomes.

This study had limitations that are common to studies based on retrospective database analysis. The MarketScan databases did not have clinical information such as detailed asthma symptoms lung functions tests to assess the asthma severity more accurately. Although we controlled for the demographic factors such as age and gender, characteristics such as race and ethnicity were not available in the Market Scan databases that might have introduced some bias to the analysis. According to the literature of healthcare utilization, race and ethnicity are very important predictors of healthcare utilization. Cultural differences, multiple languages influence the access of health services. In general because of the cross-cultural difficulties and/or language barriers people belonging to minority groups have been observed to have reduced utilization than whites. ${ }^{26}$ Race and ethnicity are also believed to be major predictors of receiving several treatments and procedures ${ }^{27}$ Regarding the chronic conditions such as asthma a study done by Agency for Healthcare Research and Quality (AHRQ) revealed that only 7\% of African Americans and only 2\% of Hispanic children were prescribed routine asthma medications compared to the $21 \%$ of Caucasians. ${ }^{27}$ However the data used for this study did not provide any information on this key predictor of health utilization.

Regarding the demographic characteristics, the data did not allow information on income level or availability of secondary insurance that may also significantly influences health services utilization. It has been documented by that those who have higher income levels have better access and therefore higher rates of healthcare utilization compared to the poor population. Availability of secondary insurance may also influence utilization of health services as it provides additional financial assistance along with the primary insurance.

The adherence was measured based on the pharmacy claims for the medication but the presence of pharmacy claim does not guarantee use of medication by the patient. Another aspect that is not considered in this analysis is technique in using inhalation devices. Number of asthma patients misuse their metered inhalers. ${ }^{28}$ Although by definition they are included in the more compliant groups they might be having poor health outcomes because of improper use of inhaler device. It is not possible to measure outcomes attributed to the improper inhaler use by using claims database. The study also had limitation inherent to the analysis of secondary data such as potential errors in data collection, coding errors and omission. 
Further, this study also examined the outcomes such as Emergency Room (ER) visits, hospitalizations and the use of Short Acting Bronchodilators (SAB) to confirm how the better adherence is translated into better outcomes. Analyzing the cost related non-adherence and outcomes for the patients before getting stepped up helped us to understand if the higher cost sharing is associated with the outcomes that might result in to worsening the severity of asthma from mild to moderate.

\section{$\underline{1.7 \text { Terms and Definitions }}$}

Administrative claims data: Administrative claims data are the electronic records of bills submitted by health care providers, hospitals, pharmacies, for office visits, hospital stays, or other encounters, or for sales of drugs or supplies.

Asthma: A common disorder in which chronic inflammation of the bronchial tubes (bronchi) resulting in swelling and narrowing the airways.

Benefit cap: Benefit caps limit the coverage for a specific amount and when the prescription drug expenditure reached that limit, patients do not receive any coverage and have to spend the entire cost out of pocket.

Co-morbidity index: Comorbidity index captures the combined effect of all other diseases an individual patient might have other than the primary disease of interest.

Controller medication: Controller medications are medication that are required to consume over a period of time to control airway inflammation and help prevent asthma exacerbations from occurring.

Co-payment: A copayment, or copay, is a capped contribution defined in the policy and paid by an insured person each time a medical service is accessed.

Demand curve: Demand curve is the graph illustrating the association between the price of a certain commodity, and the amount of it that consumers are willing and able to purchase at that given price.

Direct costs: Costs related to the provision of medical care, including the screening, prevention, diagnosis, and treatment of diseases. ${ }^{29}$

Emergency room services: Include visits to healthcare providers in an emergency room. 
Formulary: Formulary is a list of prescription drugs approved for coverage under a specific health insurance plan.

Indirect costs: Costs of illness related to loss in productivity by the individual who is ill and by family members who care for that individual. ${ }^{29}$

Medicare Part D: Medicare Part D is a federal program to subsidize the costs of prescription drugs for Medicare beneficiaries in the United States.

Medication adherence: Adherence to (or compliance with) a medication regimen is generally defined as, "the extent to which patients take medications as prescribed by their health care providers." 37

Medication Possession Ratio (MPR): The Medication Possession Ratio (MPR) is a formula used to determine compliance that is measured from the first to the last prescription, with the denominator being the duration from index to the exhaustion of the last prescription and the numerator being the days supplied over that period from first to last prescription.

Moral hazard: Moral hazard is defined as the change in behavior when people are insulated from risk.

Out of pocket costs: The portion of the claim that the patient or enrollee is obligated to pay.

Outpatient services: Visits to physicians and other medical providers seen in hospital outpatient departments.

Pharmacoepidemiology: Pharmacoepidemiology is the study of the use of and the effects of drugs in large groups of people.

Prevalence: the prevalence of a disease is defined as the total number of cases of the disease in the population at a given time, divided by the number of individuals in the population.

Reliever medication: Asthma reliever is a drug that provides relief from asthma symptoms and is the most commonly used asthma medication. 
Step-up therapy: When asthma symptoms are not controlled by the inhaled corticosteroids alone patients are recommended to take additional controller medications along with the minimum dose of ICS.

\subsection{Organization of the Dissertation}

This dissertation is organized into five chapters. Chapter I deals with the introduction and problem statement along with objectives and specific aims of this study. Chapter II provides a review of the literature covering literature on cost sharing and asthma controller treatment options. Chapter III presents the methods used in the research, while Chapter IV provides the results of the research. Chapter V is a discussion of findings and possible future directions that the research may suggest. 


\section{Chapter II: Literature Review}

This chapter is organized to provide information from the current literature that deals with cost sharing, its impact on utilization of prescription drugs and issues related to asthma controller drug adherence.

In today's health care arena prescription drugs play an indispensible role. Especially for chronic conditions such as asthma, hypertension, diabetes, prescription drugs are instrumental in managing the disease condition and controlling symptoms. However, the recent surge in cost of prescription drugs with double digit inflation has worried many. ${ }^{31}$ Besides the patients consuming these drugs, major payers such as insurance companies are most affected by the rise in cost. In order to offset the increasing expenditure on prescription drugs, insurance companies have different strategies to design the pharmacy benefit component.

Traditionally researchers considered healthcare as unpleasant and thus not likely to be sensitive to price changes. However, the largest social science experiment known as RAND Health Insurance Experiment (HIE) demonstrated phenomenon of moral hazard even in the field of health insurance by measuring people's response to the price of health care. ${ }^{32}$ Moral hazard happens when people tend to utilize more expensive medical goods and services when they have insurance to cover the cost than when they don't have insurance. This increase in spending resulting from the lower price to the user because of insurance is called 'moral hazard'. ${ }^{2}$ RAND HIE showed that the people behave in a different way, regarding the use of medical care and total spending, when they have insurance. The HIE found that people who were receiving free healthcare used $30 \%$ more healthcare than the people that had deductible. ${ }^{32}$ Same principle applies in case of prescription drug coverage as well. Patients having prescription drug coverage are likely to use more drugs than they would normally use because they are insulated from the actual price. To control the moral hazard and unnecessary spending on healthcare services, insurance companies started using cost sharing strategies such as annual deductible and copayments. As the drug benefit plans are supplementary to the health insurance policy different cost sharing strategies are introduced to the drug plans as well.

Initially some benefit plans implemented closed or very restrictive formularies providing insurance coverage to only a limited number of drugs or therapeutic classes. This led to major dissatisfaction among patients as well as health care providers such as physicians. ${ }^{33}$ Because of the unpopularity of these plans, many insurance companies adopted a benefit structure covering majority of drugs but classified them into different tiers with different co-payment level. The main idea behind this arrangement was to 
encourage patients to use generic drugs or cheaper brands whenever available. From the patient's perspective, depending upon what medication they are taking, out of pocket cost is determined in the majority of insurance plans. Besides the formulary restrictions, some plans also use benefit caps to avoid excessive drug utilization. Benefit caps limit the coverage for a specific amount and when the prescription drug expenditure reached that limit, patients so not receive any coverage and have to spend the entire cost out of pocket. For example Medicare Part D beneficiaries receive coverage only up to \$2400 (in 2007) and beyond that they have to spend out of pocket until their expenditure reaches $\$ 5451$. Benefit caps also include restrictions on number of prescription drugs covered for an individual. Medicaid beneficiaries receiving prescription drug coverage in many states are restricted to the number of prescription drugs that can be covered. Benefit caps also have a negative impact on utilization of prescription drugs. Soumurai et al. ${ }^{34}$ carried out a comparison between prescription drug utilization in New Hampshire (Medicaid plan limit of 3 drugs per month per patient) and New Jersey (no such cap existed). They found a $35 \%$ reduction in drug utilization among patients in New Hampshire.

According to the theory of economics, raising the cost sharing levels can have following economic effects ${ }^{35}$ 1) Utilization: Higher prices are expected to shift patients upwards in the demand curve and closer to the economically optimal amount, resulting in a decrease in utilization.2) Substitution: If the drug costs are too expensive, patients are likely to search for less expensive alternative. For example in case of asthma, patients might choose to consume excessive amount of short term relievers to get symptomatic relief that are cheaper than the controllers to save money affecting the controller drug utilization. 3) Value: A price increase would result in decrease in consumption of drugs that are valued lower by the patients and as a result patient would be insensitive to the price increase in high value drugs such as life sustaining drugs. However, this effect is expected only if patients have adequate information to evaluate cost to benefit ratio which is generally not observed. ${ }^{35}$ Therefore even though the controller drugs are valuable to the asthma patients having moderate severity, the observed adherence levels are still lower.

Therefore it is very important and difficult to maintain the optimum cost sharing levels that are high enough to curb the excessive utilization but at the same time are not discouraging patients from taking the required amount of medication.

\section{$\underline{2.1 \text { Cost Sharing and Prescription Drugs }}$}

The literature on cost sharing for prescription drugs is comprised of a great number of studies and articles published in various peer reviewed journals. The various 
aspects of cost sharing such as co-pay, co-insurance, formularies, tiered structure and other methods used to control drug prices make the literature on cost sharing dispersed across several fields and not restricted to any specific settings as in case of a medical intervention. The literature on cost sharing mainly focuses on the impact of cost sharing on: 1) drug spending; 2) adherence/compliance/persistence; and 3) health Outcomes.

\subsubsection{Drug spending}

There are experimental as well as observational studies documenting effects of cost sharing levels on healthcare expenditure of prescription drugs at patient level. Data published from the RAND Health Insurance Experiment (HIE) is one of the oldest published studies in the US documenting the effect of cost sharing on expenditure. ${ }^{32}$ One of the important findings from HIE was that individuals subject to higher coinsurance level tend to use less care and their response to higher cost sharing in case of prescription drugs is similar. ${ }^{36,37}$ A study done by Leibowitz et al. using the data from HIE documented that the co-insurance at $95 \%$ can drop the expenditure to $57 \%$ of the patients receiving free care plan. ${ }^{4}$ Another study published from the HIE showed the patients having free care were found to use $85 \%$ more antibiotics. ${ }^{36}$

Although the studies based on HIE used relatively older data from RAND study, there are number of studies including some recent ones, analyzing the relationship between co-insurance and drug spending. ${ }^{38-40}$ Almost all of the studies available in the current literature examining the relationship between co insurance and drug spending, have successfully documented the reduction in drug expenditure by increasing the coinsurance levels. The reduction in expenditure is observed in all age groups including children, adults and elderly. Other than the US, studies done in other countries such as Canada $^{38}$ and Sweden ${ }^{41}$ also have confirmed the finding from the US studies. The literature on cost sharing levels and drug spending provides conclusive data on the success of implementing cost sharing strategies on limiting the drug spending. Besides the cost sharing strategies, several studies have also documented the success of formulary restrictions.

\subsubsection{Adherence and compliance}

Adherence and compliance to the various treatments is a key issue in the health research literature and studies on them form a vast body of literature. The studies ${ }^{42-44}$ showing cost effectiveness of prescription drugs over the other health care resources such as ED, surgery, hospitalization etc. add to the need to study compliance and adherence 
with medications. Examples from the current literature, such as cost effectiveness of warfarin therapy to prevent stroke, ${ }^{43}$ immunosuppressive drugs for kidney transplants, ${ }^{44}$ highlight the importance and need of examining drug utilization and factors affecting it to achieve the maximum cost effectiveness. ${ }^{42}$

One of the most frequently cited studies on cost sharing and adherence is work done by Goldman et al. ${ }^{45}$ In this study they used pharmacy medical claims data covering privately insured beneficiaries aged 18-64 in 52 health plans. They examined impact of co-payment increase with a broad range of therapeutic classes. They found an inverse relationship between co-payment and drug utilization across all therapeutic classes they studied. Reduction in drug utilization ranged from 25\%-45\%. Landsman et al. also reported similar findings using Medication Possession Ratio (MPR) as an outcome measure. They focused on members from managed care plans and included 9 drug classes in their study. Key finding from this study was reduction in MPRs in 7 of 9 drug classes. A study done by Ellis et al. examined enrollees with statin prescriptions in a managed care organization. They also found that the statin therapy duration decreased with increase in copayment from $\$ 10$ to $\$ 20{ }^{46}$

However there is a repeatedly cited gap in the literature about studies focusing on relationship between cost sharing and adherence or compliance. Many studies examining this relationship in the US have focused on Medicaid populations, most of which have no or very low cost sharing plans. Outside the U.S. there are several studies published in Canada but again in Canada there are very limited variations in cost sharing as compared to the US.

Even though the literature has considerable evidence on how increased cost sharing results in a decrease in utilization, the current literature on cost sharing lacks studies comparing drug classes within a clinical condition and analyzing consequent outcomes. Such comparison provides key data for decision makers and formulary developers in setting up cost sharing levels for a drug plan. In case of asthma, there are very few studies published that examine the link between cost sharing and controller regimen adherence.

\subsubsection{Asthma related healthcare resources utilization outcomes}

While studying adherence to different treatment regimens, it is also important to study healthcare resources utilization outcomes to confirm that the better adherence is translated in to better outcomes. In this section we will review studies that dealt with effects of cost sharing on various healthcare resources utilization outcomes. 
Most of the studies evaluating effect of cost sharing on health outcomes used health services utilization as a measure of health outcomes. Although health services utilization is not a direct measure of health status or quality of care, increase in utilization of services such as emergency room visits, hospitalization, inpatient and outpatient visits indicate poor health outcomes. A number of studies ${ }^{15,47-49}$ reported no change in utilization of relatively less expensive health services such as physician office visits, home health visits and outpatient visits. However the cost sharing changes evaluated in these studies were small. Furthermore the studies that did not find any association between health services utilization and high cost sharing levels had focus on patients suffering from a specific condition such as myocardial infarction. Study done by Pilot et al. ${ }^{15}$ measured the effects of prescription drug cost sharing among the patients recently hospitalized for acute myocardial infarction and therefore they may have been insensitive to the price changes.

In terms of more expensive health services utilization such as inpatient visits or ER visits, a study done by Christian-Herman et al. ${ }^{50}$ found that following a large change in cost sharing levels in a Medicare HMO plan, the inpatient visits increased significantly. Nevertheless the increase was not observed in all the diagnostic groups they studied. No significant increase in number of inpatients visits was observed among the patients suffering from congestive heart failure or coronary heart disease but on the other hand patients suffering from diabetes mellitus had increased number of inpatient visits. Another study done by Tamblyn et al. ${ }^{51}$ measured the effects of $25 \%$ raise in copayment levels among elderly and welfare recipient in Canada. They found that patients who reduced their consumption of essential drugs as a response to the copayment raise had greater number of adverse events such as hospitalization, long-term care admission and death.

A study conducted by Heisler et al. ${ }^{13}$ measured health outcomes as self reported health status, and found that the cost related restrictions among elderly patients were associated with decrease in their self-reported health status. They also found association of cost related restriction and higher rates of non fatal heart attacks or stroke among those with preexisting cardiovascular condition.

In a nutshell, cost sharing levels have mixed effects on the health outcomes such as hospitalization, ER visit, outpatient and inpatient visits. The effects vary considerably depending upon the disease condition focused in the study. 


\section{$\underline{2.2 \text { Cost Sharing and Use of Asthma Medication }}$}

\subsubsection{Brief description of asthma}

Asthma is a chronic disorder characterized by inflammation to airway. According to the asthma literature, asthma is one of the major causes of work and school absence. ${ }^{52}$ It has been estimated that costs resulting from lost workdays due to asthma in adults are over $\$ 800$ million per year. An additional $\$ 900$ million per year is lost because of workdays missed by parents caring for children with asthma. ${ }^{53}$ It is also one of the common reasons leading to ER visit and hospitalization. According to a study, the estimated annual cost of asthma-related hospitalizations is over one billion dollars ${ }^{54}$ also the projected yearly cost of asthma-related emergency room visits is close to $\$ 300$ million. ${ }^{53}$ From an economic perspective asthma costs approximately $\$ 13$ billion each year in the US. ${ }^{55}$

In terms of mortality, approximately 5000 people die of asthma in the US. ${ }^{52}$ Based on an estimate by National Center for Environmental Health (NCEH) ${ }^{56}$ there are 20 million asthma cases in the United States. According to National Institute of Allergy and infectious diseases (NIAID) ${ }^{57}$ asthma is the most common chronic condition in children and sixth most common chronic condition in general in the United States

Asthma is included as a key component in the respiratory disease chapter of the Healthy People 2010 objectives. ${ }^{58}$ These objectives are: $24-1$, reduce asthma deaths; $24-$ 2 , reduce hospitalizations for asthma; 24-3, reduce hospital emergency department visits for asthma; 24-4, reduce activity limitations among persons with asthma; 24-5, reduce the number of school or work days missed by persons with asthma because of their asthma; 24-6, increase the proportion of persons with asthma who receive formal patient education, including information regarding community and self-help resources, as an essential part of the management of their condition; 24-7, increase the proportion of persons with asthma who receive appropriate asthma care according to the NAEPP guidelines; and 24-8, establish in greater than 25 states a surveillance system for tracking asthma deaths, illnesses, disabilities, impact of occupational and environmental factors on asthma, access to medical care, and asthma management. ${ }^{58}$

\subsubsection{Asthma severity classification}

NHLBI classifies asthma by its severity. The classification based on severity is widely used by health care professionals. As asthma treatment choice is largely 
dependent upon the severity levels, it is useful to briefly review the asthma severity levels. These severity levels are based on frequency and severity of asthma symptoms. The severity levels according to NHLBI guidelines are outlined in Table 1.

Treatment regimens for children and adults (age 5 and above) are decided based on the severity level. Patients having mild intermittent asthma are mostly treated with quick-relief medicines only, while patients having severe persistent asthma are treated with combination therapy of one or more daily controller medicines along with the use of quick-relief medicines as needed.

\subsubsection{Asthma treatment options}

Although asthma can't be cured, it can be controlled. Current guidelines also recommend treatment for asthma to be focused on controlling the inflammation. Monitoring the symptoms and avoiding asthma triggers is considered to be the first step in asthma control. Besides avoiding the asthma triggers, guidelines recommend use of medications to achieve adequate control. The asthma medications are broadly categorized in two types of drugs: 1) quick relief medications, and 2) long term control medications. The quick relief medications are short acting bronchodilators such as metaproterenol (Alupent, Metaprel), ephedrine, terbutaline (Brethaire) and albuterol (Proventil, Ventolin). The long term control medication are inhaled or orally administered anti inflammatory steroid such as unisolide (AeroBid), triamcinolone (Azmacort) and beclomethasone (Beclovent and Vaceril), Long-acting inhaled $\beta_{2}$-agonist (LABA) and Leukotrine receptor Antagonist (LTRA),Theophylin etc.

The short acting medications are known to produce symptomatic relief but they do not contribute in controlling the chronic inflammation itself in asthma cases. However the controller drugs do not show immediate symptomatic relief but help in controlling the chronic inflammation itself. Because of these properties, the short acting dilators are being recommended for 'as needed' or 'rescue' basis only. ${ }^{8}$ Patients having persistent asthma are advised to take both classes of medication.

Within the controller medications, ICS are proven to be most effective and patients are suggested to start with minimum possible dose of ICS therapy. For the patients that require more control, guidelines recommend addition of LABA or LTRA to the existing dose of ICS. The clinical evidence is not conclusive towards any of these add on therapies as the clear dominant over another. 
Table 1 Asthma severity definition according to NHLBI guidelines

\begin{tabular}{|c|c|c|c|c|}
\hline $\begin{array}{l}\text { Asthma } \\
\text { Severity }\end{array}$ & Intermittent & Mild & $\begin{array}{l}\text { Persistent } \\
\text { Moderate }\end{array}$ & Severe \\
\hline Symptoms & $\leq 2$ days/week & $\begin{array}{c}>2 \text { days/week } \\
\text { but not daily }\end{array}$ & Daily & $\begin{array}{c}\text { Throughout } \\
\text { the day }\end{array}$ \\
\hline $\begin{array}{l}\text { Nighttime } \\
\text { awakenings }\end{array}$ & $\leq 2 \mathrm{x} /$ month & $3-4 x /$ month & $\begin{array}{c}>1 \mathrm{x} / \text { week but } \\
\text { not nightly }\end{array}$ & $\begin{array}{c}\text { Often } \\
7 \mathrm{x} / \text { week }\end{array}$ \\
\hline $\begin{array}{l}\text { SAB use for } \\
\text { symptom } \\
\text { control }\end{array}$ & $\leq 2$ days/week & $\begin{array}{c}>2 \text { days/week } \\
\text { but }>1 x / \text { day }\end{array}$ & Daily & $\begin{array}{l}\text { Several } \\
\text { times per } \\
\text { day }\end{array}$ \\
\hline $\begin{array}{l}\text { Interference } \\
\text { with normal } \\
\text { activity }\end{array}$ & None & $\begin{array}{c}\text { Minor } \\
\text { limitation } \\
\end{array}$ & $\begin{array}{c}\text { Some } \\
\text { limitation }\end{array}$ & $\begin{array}{c}\text { Extremely } \\
\text { limited }\end{array}$ \\
\hline
\end{tabular}

Source: National Heart, Lung and Blood Institute (NHLBI) Clinical practice guidelines, Expert Panel Report 2: guidelines for the diagnosis and management of asthma. $2008 .{ }^{9}$ 


\subsubsection{Add on therapy with LABA}

LABA are potent airway dilators and have a long term effect of chronic obstruction caused by asthma. Combining a LABA with an ICS has shown a greater improvement in the control of symptoms and in lung function than doubling the dose of the $\mathrm{ICS}^{59,60}$ A double-blind, randomized, parallel-group study involving 852 patients done by Pauwels et el ${ }^{60}$ demonstrated that, the rates of severe and mild exacerbations were decreased by $26 \%$ to $40 \%$, when formoterol (LABA) was added to the lower dose of budesonide (ICS). A study known as GOAL study has confirmed this data by conducting a randomized, double-blind, parallel-group study of 3,421 patients with uncontrolled asthma. ${ }^{61}$ This study concluded that asthma patients achieved control on asthma symptoms with combination of inhaled Salemterol/fluticasone (LABA+ICS) more rapidly and at a lower dose of corticosteroid than with combination of inhaled fluticasone (ICS) alone.

\subsubsection{Add on therapy with LTRA}

Leukotriene receptor antagonists (LTRA) are oral medications that act by blocking chemical mediators that can lead to inflammation in the airways. LTRA work to suppress the airway inflammation and thus produce mild bronchodilation. ${ }^{62}$ Several studies have demonstrated efficacy of LTRA along with low doses of ICS in both adults and children. ${ }^{63,64}$ In a study called as COMPACT (Clinical Outcomes with Montelukast as a Partner Agent to Corticosteroid Therapy) study, Price et al. ${ }^{65}$ demonstrated the efficacy of Montelukast as adjunct to Budesonide (ICS). A recent placebo controlled study involving 639 patients on Montelukast (LTRA) for 16 weeks showed decrease in the exacerbation frequency. ${ }^{66}$

Even though the safety and efficacy of adding LTRA is established in the current literature, the relative efficacy to addition of LABA is questioned. A study done by Busse and coworkers ${ }^{67}$ compared the addition of salmeterol (LABA) or zafirlukast (LTRA) to low doses of inhaled corticosteroids, found considerably better improvement in lung function and symptom control with the addition of the LABA as compared with a LTRA. There are also a few studies ${ }^{68-70}$ documenting no additive benefit of LTRA in asthma.

\subsubsection{Adherence to asthma controller drugs}

With the projected $\$ 13$ billion in direct and indirect costs asthma puts a significant burden on US economy. To achieve the best control over asthma, continuous 
treatment that avoids recurring exacerbations is very important. Although asthma is considered as mild illness which should be managed by ambulatory care, the one third of the total direct costs is related to emergency department use and hospitalization. ${ }^{71}$ Lately a study showed that a large portion of these costs are attributable to the uncontrolled asthma. According to the study, primary reason behind the uncontrolled asthma is underuse of prescribed therapies such as asthma controller drugs. ${ }^{71}$ Despite the recommendations from national guidelines, several studies have reported poor average rates of adherence to the controller medications among children ${ }^{72-74}$ as well as adult populations ${ }^{75,76}$ suffering from asthma.

A study done by Legorreta et al. ${ }^{76}$ found that overall, adherence to National Asthma Education Program (NAEP) guidelines was poor especially with the use of preventive drugs. Furthermore the survey respondents that indicated to have asthma inhaler, only $54 \%$ of them used it daily. Factors such as age (older), duration of asthma (longer), increasing current severity of disease, were found to be associated with the controller drug use. Jatulis et al. ${ }^{75}$ analyzed adherence to the National Heart, Lung, and Blood Institute (NHLBI) guidelines in California and they also found low level of antiinflammatory steroids usage despite the emphasis in guidelines.

Lower adherence to the controller drugs is also observed among asthma patient with the moderate to severe asthma levels. These patients are in more need of controller drugs and lack of controller drug use makes them more vulnerable to the asthma related morbidity and mortality. A study called as TNEOR focused on patients with moderate or severe asthma categories and found the lack of control in the study population.

The literature on asthma controller medication adherence strongly indicates a significant lack of adherence to the controller drugs among asthma patient populations across all age groups and asthma severity levels. Also enough evidence was found from current literature correlating the lack of adherence to the controller drug with the increased consumption of the other healthcare services such as ER visits and worsening of the heath status of asthma patients.

\subsubsection{Adherence measures}

In this study we used MPR to measure adherence to the asthma treatment regimen. However, various different methods are also used to assess the treatment adherence. Traditionally the methods used were pill counting, journals, electronic measurement devices, biochemical tracers, questionnaires and more recently analysis of pharmacy claims databases are used to assess the adherence to treatment regimens. 
Studies that use self reported adherence methods ask patients whether they missed doses and also reasons if they ever missed any. ${ }^{77}$ Patients are required to mention their current prescriptions and the average number of tablets missed per day, week, and month. The strength of this method lies in its fast and easy format to administer and it also offers thorough information about utilization patterns, patient perception of treatment and barriers to access of treatment. However, weakness of this technique is it relies on patient's memory and honesty. In case of asthma medication utilization Brooks et al. ${ }^{77}$ developed a multi-item, self-reported scale to assess patient adherence to the asthma inhalers. This scale was supported by the results and because it takes less than five minutes to complete, it also demonstrated ease of use.

More recently the widely used method to calculate adherence is to conduct retrospective analysis of insurance claims databases. Analyzing claims data has been suggested as an appropriate method for several measures such as assessment of quality of care, research in pharmacoepidemiology, evaluation of health care appropriateness and also cost and utilization studies. ${ }^{78}$ When direct measurement of utilization is not feasible, pharmacy claims databases are recommended as most appropriate to measure adherence and compliance. ${ }^{78}$ Several studies ${ }^{78-80}$ recommend use of pharmacy claims data to evaluate medication compliance and adherence. The adherence rate given by administrative data does not provide direct information on medication utilization information, but rather provides evaluation of medication possession. Adherence calculations using administrative claims data are based on the assumption that that patients use the drug as prescribed from the day of dispensing, and use all medications obtained. Therefore administrative data can offer the investigator only an estimate of the maximum possible level of medication utilization. ${ }^{81}$

To measure the adherence using large claims data as source, Sclar et al. ${ }^{82}$ introduced Medication Possession Ratio (MPR). Followed by their work the MPR in now widely accepted as a measurement of drug adherence. ${ }^{83}$ Most of the times the MPR is defined as the ratio of 'sum of the days' supply of medication' to 'the total number of days in the study period.' This ratio yields values ranging from 0 to 1 . MPR successfully captures the utilization behavior however it fails short to capture characteristics such as timeliness and consistency. For example if a patient fills prescription every alternate month throughout the year and another patient fills prescription for six months only then even though their utilization behavior is different both of them will have exact same value for the MPR.

Besides MPR, literature search on adherence measurement using pharmacy claims database also showed several methods to measure medication adherence. Some of the most frequently cited measures include, Continuous Measure of Medication Acquisition 
(CMA); Continuous Multiple Interval Measure of Oversupply (CMOS); Medication Refill Adherence (MRA); Continuous Measure of Medication Gaps (CMG); Continuous, Single Interval Measure of Medication Acquisition (CSA); Proportion of Days Covered (PDC); Refill Compliance Rate (RCR); Medication Possession Ratio, modified (MPRm); Dates Between Fills Adherence Rate (DBR); and Compliance Rate (CR). Hess et al. ${ }^{81}$ reviewed studies based on all these measures and concluded that CMA, CMOS. MPR and MRA produce identical results in measuring adherence while CMG and PDC produce slightly lower and CR, MPRm, RCR and CSA produce higher rates of adherence.

\subsubsection{Cost sharing and controller drugs utilization}

Although cost sharing plays an important role in adherence to the medications for chronic conditions, the effect of it among asthma population is not been explored extensively. Despite the poor adherence levels are reported abundantly in the current literature, there is limited information available on association of it with the cost sharing levels. Also the currently available studies focusing on cost sharing and utilization of asthma medication did not assess utilization of asthma drugs using adherence measures such as MPR.

When searching for the articles on costs sharing effects and asthma controller utilization, only two major studies were found in the US. Interestingly, the results from both the studies were contradictory to each other. First study found that although the cost sharing levels increased from 1995 to 2000, utilization of controller drugs among asthmatics was not affected significantly. ${ }^{25}$ Conversely another study done by Goldman et al. ${ }^{45}$ explored relationship of cost sharing and utilization of prescription drugs among multiple chronic conditions (based on drug classification in the red book) found that doubling the cost sharing levels resulted in to $32 \%$ drop in overall asthma drug utilization. None of these studies specifically focused on the asthmatics with asthma severity levels 'moderate to severe' (patients that need more that one controller drugs). Also both the studies did not capture effects of cost sharing levels on health outcomes such as emergency room visits, hospitalization and SAB utilization. In terms of cost sharing effects on utilization of asthma medications among children, Ungar et al. ${ }^{84}$ did a study focusing on cost sharing effects on asthma medication utilization among children in Ontario, Canada. In this study they found that the cost sharing levels affected consumption of asthma medication among children. Higher cost sharing levels resulted in to significantly lower consumption of asthma medications such as controller drugs. 


\subsection{Gaps Addressed by This Study}

Work done prior to this study has provided important information about cost sharing and its impact on various factors such as drug spending, drug utilization and adherence to the treatment regimen. However when it comes to impact of cost sharing on adherence to medication within a chronic condition such asthma, there are very few studies available. The literature on adherence with asthma controllers has documented the lower adherence to controller regimen than the recommended guidelines, but there are a limited number of studies examining the association of lower utilization to the out of pocket cost. Also the results from previous studies are not consistent with each other and do not measure utilization of medications using standardized adherence measures such as MPR. Poor adherence to controller regimen is characterized by increased morbidity, mortality and increased utilization of health care resources. This gap can be bridged by adding more studies to the current literature that establish the link between cost sharing and adherence to medication with respect to a particular chronic condition such as asthma.

Rising costs of prescription drugs are accelerating the need to introduce greater cost sharing in US managed care programs but the information on how successful these policies would be to control the overall cost and improve the health status is limited. In case of chronic conditions such as asthma, prescription drugs comprise an important part of treatment and management of the disease. In this study we focused on the asthma patients having moderate to severe asthma levels and analyzed what impact cost sharing has on the utilization of controller drugs. 


\section{Chapter III: Methods}

The main focus of this study was to evaluate the impact of prescription drug cost sharing on utilization of asthma controller medications and to analyze the health outcomes associated with the utilization of controller drugs. The study population included asthma patients from an administrative claims data within the age group 5-65 who are stepped up from single controller therapy to the dual controller therapy.

To investigate the impact of cost sharing on adherence to the treatment options we utilized retrospective longitudinal study design using administrative claims database. This was an observational study and the data for this study came from MarketScan commercial database. The study period for each patient started six months prior to the patient's index medication and continued for six months post index. The asthma patients were defined to be diagnosed with 'moderate persistent' asthma if they were stepped up from one controller medication to more than one controller medications. Whether the patients were stepped up or not was determined by analyzing their prescription drug records.

\section{$\underline{3.1 \text { Study Design }}$}

The asthma patients having prescription drug history of only one controller (ICS) were selected among them those who were found to have additional controller drug (ICS + LABA or ICS + LTRA) in the claims history were selected for the study. Controller drug utilization pattern for these patients before and after getting stepped up was studied using MPR as the adherence measure. Presence of additional controller medication (ICS + LABA or ICS + LTRA) was the index date prescription and 6 months prior and after the index date defined the study period. Figure 2 illustrates the research design used in this study.

To investigate the impact of cost sharing on adherence to the treatment options we utilized retrospective longitudinal study design using administrative claims database. This was an observational study and the data for this study came from MarketScan commercial database. The study period for each patient started six months prior to the patient's index medication and continued for six months post index (Figure 2). The asthma patients were defined to be diagnosed with 'moderate persistent' asthma if they were stepped up from one controller medication to more than one controller medications. Whether the patients were stepped up or not was determined by analyzing their prescription drug records. 


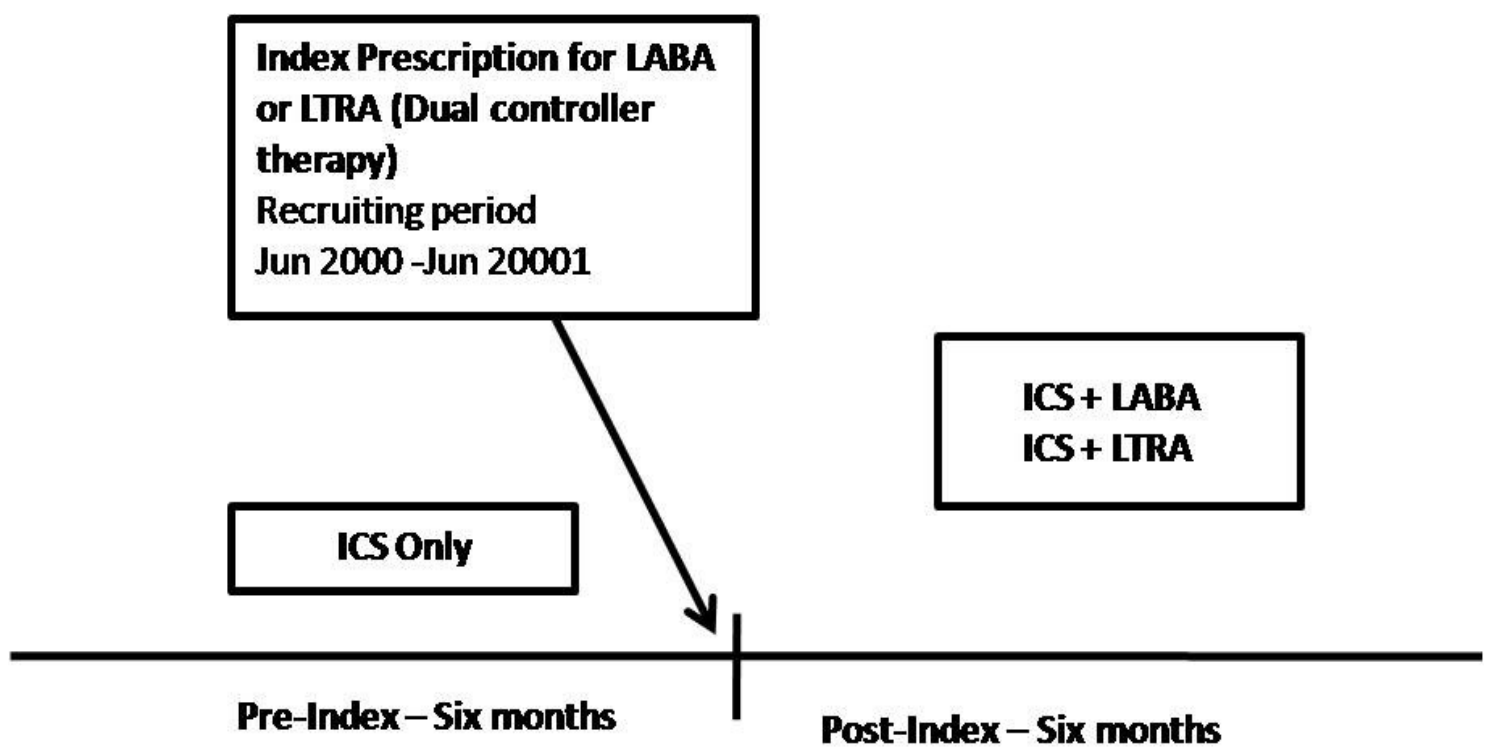

Figure 2 Study design 
The asthma patients having prescription drug history of only one controller (ICS) were selected among them those who were found to have additional controller drug (ICS + LABA or ICS + LTRA) in the claims history were selected for the study. Controller drug utilization pattern for these patients before and after getting stepped up was studied using MPR as the adherence measure. Presence of additional controller medication (ICS + LABA or ICS + LTRA) was the index date prescription and 6 months prior and after the index date defined the study period.

\section{$\underline{3.2 \text { Study Population }}$}

For this study we needed patients diagnosed with asthma and who are stepped up from a single controller drug (ICS) to a combination of ICS + LABA or LTRA. To formulate the final study sample, we applied following inclusion and exclusion criterions.

\subsubsection{Inclusion criteria}

The participants for this study were selected based on their principal or secondary diagnostic claim (ICD-9 493.XX) for asthma during the pre index period. All subjects included for this study were in the age group from 5 to 65 . All asthma patients having at least one claim of ICS and no claims for any other controller add-on were recruited for the final sampling. Among these patients those that were found to have at least one additional prescription of LABA or LTRA along with at least one claim for ICS were included in the final sample.

\subsubsection{Exclusion criteria}

To ensure the evaluation of patient outcomes is based on asthma; patients were excluded from analysis if they were diagnosed with any of the following conditions in the pre or post study period. The conditions included chronic obstructive pulmonary disease (COPD), bronchopulmonary dysplasia and respiratory distress syndrome. Also the patients that switched medications from one controller add on to another controller add on were excluded from this analysis. Patients not enrolled continuously for the study period were also excluded from the study. 


\section{$\underline{3.3 \text { Data Source }}$}

This study utilized data from the Medstat MarketScan databases (Copyright 2001, The Medstat Group, Inc., All Rights Reserved.) The MarketScan databases are based on privately insured paid medical and prescription drug claims. The data is collected from approximately 45 large employers, health plans, and government and public organizations on person specific clinical utilization, expenditures, and enrollment across inpatient, outpatient, prescription drug, and carve-out services. Including the commercial insurance companies the databases consist of data from almost 100 payers.

The MarketScan Databases are based on a calendar year incurred period and are produced as a snapshot in time. The databases are created by combining the standard variables of the individual databases (data contributors) and also links between years of data are established across all data types. The amount of time between the date of service on the claim and the date payment is made, also known as Claims lag periods fluctuate considerably across the roughly 100 insurance carriers in MarketScan. Because of this, the data are collected when close to $100 \%$ of claims have been paid, which takes about six months after year end.

Various edits and checks are done to confirm the reasonableness and validity of the data. Reasonableness is established by checking the relationship between two or more fields against norms. For selected fields, including zip codes, diagnosis codes, procedure codes, date(s) of service, gender and age, validity checks are carries out to compare recorded values to lists of probable valid values for those fields. The improper coding is fixed by flagging and recommending it to the carrier or data processor for quality improvement actions.

\section{$\underline{3.4 \text { Measures }}$}

According to the theoretical framework of this study we first measured effect of cost sharing levels (Exposure variable) on controller drug adherence (intermediate outcome) and then measured effect of adherence on health outcomes such as ER visits, hospitalization and SAB use (End outcomes). Variables that can be predisposing for asthma drug utilization ${ }^{18}$ and also were available in databases included age gender and location. Data on race and ethnicity could not be obtained because of the limitation of administrative claims databases. Cultural differences, multiple languages influence the access of health services. In general because of the cross-cultural difficulties and/or language barriers people belonging to minority groups have been observed to have reduced utilization than whites. ${ }^{26}$ It has been documented that the race and ethnicity are 
major predictors of receiving several procedures and treatments. In one study investigators found that out of nine hospital procedures only five procedures were significantly less common among African American patients than among Caucasian patients. Other AHRQ studies have also revealed that the additional disparities exist for various chronic conditions including asthma. Regarding the use of necessary medications among pediatric asthma patients compared to $21 \%$ of Caucasian patients only $7 \%$ Afirican American and 2\% of Hispanic children were prescribed routine asthma medication to prevent the asthma related. However, as the insurance claims data do not allow information on race and ethnicity, the exclusion of this measure is a source of possible bias in the estimates due to the correlation of race/ethnicity with measures included in the model.

In terms of enabling resources besides the cost sharing levels study included type of health plan and pre index healthcare expenditure. For this study, the target population represented similar illness level i.e. moderate persistent asthma. In order to control for the presence of comorbid conditions which can influence the overall drug utilization ${ }^{85}$, we used Charlson's modified comorbodity index ${ }^{86}$ adapted for administrative claims databases.

\subsubsection{Exposure variable}

Cost sharing levels: Cost sharing levels were defined by determining percentage of total cost paid by the patients out of pocket. Depending upon the percentage of total cost paid out of pocket patients were categorized in to four categories. These categories were defined as $0-10 \%, 11-20 \%, 21-34 \%$ and $>35 \%$ of total cost paid out of pocket.

\subsubsection{Outcome variables}

Medication Possession Ratio (MPR): To measure the adherence to controller drugs, Medication Possession Ratio (MPR) was used. The MPR is a continuous variable assessing medication availability over multiple refill intervals. It is calculated by dividing the number of days supplied for a given medication by the number of days in the study. Possible values for MPR are between 1.0 and 0,1 indicating highest compliance and 0 indicating lowest possible compliance. MPR is used frequently in studies as a measure of compliance. The MPR provides information about whether the patient is using the proper amount of medication in a specific timeframe. In this study, MPR for the medications was calculated by dividing the number of days of supply of medication received during 180 days of follow-up. The relative MPR was determined by calculating the overall 
median MPR as reference to the individual MPR. For the analysis purpose, based on the median, patients were dichotomized in to more or less persistent users (Figure 3).

In terms healthcare resources utilization outcomes, ED visits and hospitalization among the study population were used as indicators for the health outcomes. Number of ED visits and hospitalizations were calculated for all the study participants and compared between the patients having different adherence. The total number of ED visits was summed up from the outpatient and inpatient records and total number of hospital stay days was calculated based on asthma related inpatient records. Besides ED visits and hospitalizations, utilization of SABs was also measured. Over utilization of SAB indicates the more frequent asthma symptoms and therefore indicating the poor control on the asthma. The current asthma treatment focuses on use of controllers to reduce the asthma symptoms which reduces utilization of SABs.

\subsubsection{Control variables}

Age, gender, geographical location, prescription drug expenditure, Charlson's comorbidity index were used as control variables. Age gender and location provided information about predisposing characteristics in the Anderson's healthcare utilization model. Pre-index total healthcare expenditure (inpatient and outpatient) for six months period was calculated for each patient. It served as an enabling factor since it indicates patients' financial ability to pay the cost out of pocket.

Other than the health care expenditure, type of plan variable was also included as enabling variable. Subjects were categorized in to fee-for-service and non-non-fee for service plans based on the type of plan they were enrolled in. Non-Fee-for-service plans included health maintenance organizations, noncapitated point-of-service plans, preferred provider organization, or capitated or partially captitated point-of-service plans. Fee-forservices plans included basic medical and comprehensive health insurance coverage.

\subsubsection{Charlson's comorbidity index}

Aggregate comorbidity measures are important to attribute risk factors and disease severity of the patient. In order to successfully implement the 'need' part of Anderson's healthcare utilization model, it is necessary to attribute severity levels based on comorbid conditions. A Charlson Index score, ${ }^{86}$ modified for use in administrative

databases, ${ }^{85}$ was calculated for each individual patient, using ICD-9 CM codes in the 15 secondary diagnosis field (Table 2). 


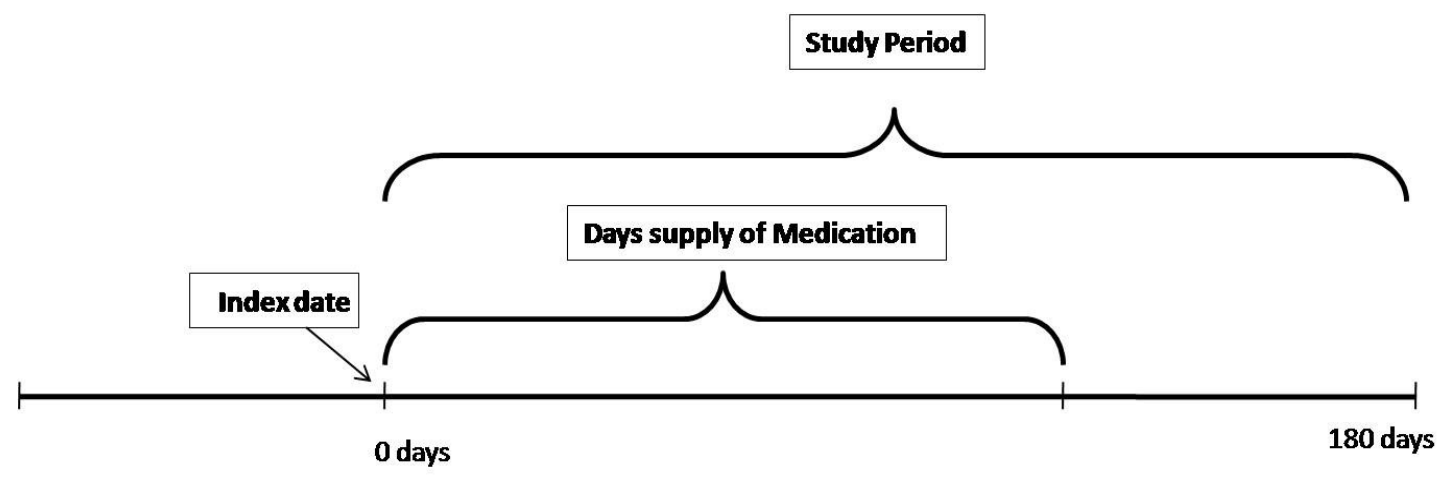

Figure 3 Example of MPR calculation 
Table 2 Comorbidity weights

\begin{tabular}{|c|c|c|}
\hline Weights & Conditions & ICD-9 Codes \\
\hline \multirow[t]{15}{*}{1} & Myocardial infarct & 410,411 \\
\hline & Congestive heart failure & $398,402,428$ \\
\hline & Peripheral vascular disease & $440-447$ \\
\hline & Dementia & $290,291,294$ \\
\hline & Cerebrovascular disease & $430-433,435$ \\
\hline & Chronic pulmonary disease & $491-493$ \\
\hline & Connective tissue disease & $710,714,725$ \\
\hline & Ulcer disease & $531-534$ \\
\hline & Mild liver disease & 571,573 \\
\hline & Hemiplegia & $342,434,436,437$ \\
\hline & Moderate or severe renal disease & $403,404,580-586$ \\
\hline & Diabetes & 250 \\
\hline & Any tumor & $140-195$ \\
\hline & Leukemia & $204-208$ \\
\hline & Lymphoma & $200,202,203$ \\
\hline 3 & Moderate or severe liver disease & $070,570,572$ \\
\hline 6 & Metastatic solid tumor & 196-199 \\
\hline
\end{tabular}

Source: D'Hoore W, Bouckaert A, Tilquin C. Practical considerations on the use of the Charlson comorbidity index with administrative data bases. Journal of Clinical Epidemiology 1996 December; 49(12):1429-33. ${ }^{85}$ 
The Charlson comorbidity index was originally designed as a measure of the risk of 1-year mortality attributable to comorbidity in a longitudinal study of general hospitalized patients. The measure was then validated for the same outcome in a cohort of breast cancer patients. Cox proportional hazard modeling was used to create its contents and weighting scheme. ${ }^{86}$ Later on it was adapted in a way that International Classification of Diseases, Ninth Revision (ICD-9), codes could be used to compute the Charlson Comorbidity Index with existing administrative data ${ }^{85}$. Using the ICD codes from the outpatient's claims for the primary or secondary diagnoses by the study population, weights were applied and individual comorbidity scores were assigned to all the study participants

\section{$\underline{3.5 \text { Statistical Analysis }}$}

\subsubsection{Cost sharing levels and adherence}

Accurately assessing the impact of cost sharing levels on adherence with controller drugs requires rich data source and advanced statistical techniques. Regression modeling, statistical tests such as student $t$ test and use of statistical software SAS (version 9.1) helped to achieve the results for this study. This methodology provided important information that will be essential in targeting future strategies to improve the controller drug utilization among asthma population.

To quantify the change in Medication Possession Ratio (adherence measure) with respect to increase in cost sharing level, multivariate least square linear regression model was built. All study participants were categorized into cost sharing levels $(0-10 \%, 11-$ $20 \%, 21-35 \%$ and $>36 \%$ ) calculated by percentage of total cost of a drug paid out of pocket and the change in adherence was evaluated. Cost sharing levels was the independent variable of interest in this model. The model was adjusted for covariates/independent variables available from the data such as gender, age past year expenditure on prescription drugs and Charlson comorbidity index. Age was squared and also included in the model as usually age has a curvilinear relationship with utilization of health services. The past year expenditure was log transformed to reduce the influence of outliers. This helped to reduce skewness of the distribution and bring it close to normal distribution.

$$
\begin{aligned}
& Y_{i}=\beta_{0}+\beta_{1} x_{i 1}+\beta_{2} x_{i 2}+\beta_{3} x_{i 3}+\beta_{4} x_{i 4}+\beta_{5} x_{i 5} \\
& \text { Where, } i=1, \ldots, n
\end{aligned}
$$




$$
\begin{aligned}
& \boldsymbol{Y}=\text { Adherence to controller drugs (MPR) } \\
& \boldsymbol{x}_{\mathbf{1}}=\text { Cost sharing levels } \\
& \boldsymbol{x}_{\mathbf{2}}=\text { Gender } \\
& \boldsymbol{x}_{\mathbf{3}}=\text { Age } \\
& \boldsymbol{x}_{\mathbf{4}}=\text { Past year expenditure } \\
& \boldsymbol{x}_{\mathbf{5}}=\text { Charlson comorbidity index }
\end{aligned}
$$

A similar regression model was built to analyze if the regression coefficient varies across patients that used ICS+LABA and ICS+LTRA.

\subsubsection{Adherence and resource utilization outcomes}

Once the relationship between cost sharing levels and adherence to controller drugs was analyzed, the asthma related health care services utilization outcomes relationship with the adherence level was analyzed by controlling the covariates. Since the adherence is also a function of some variables, it is an endogenous variable. The endogenous explanatory variable makes a non-zero correlation with the error term in the health care utilization regression.

In cases where such correlation occurs ordinary linear regression models generally produces biased estimates. To overcome this problem, if an instrument is available and used, consistent estimates may still be obtained. An instrument is a variable that correlated with the endogenous explanatory variable but does not itself have any direct impact on healthcare utilization variables. ${ }^{87}$

So finally to estimate the unbiased results, a two stage least square regression equation was built. In the first stage, the endogenous adherence variable was regressed on prescription drug cost sharing plus all explanatory variables in the health care service utilization regression equation. Since the cost sharing levels for prescription drug may influence adherence with controller drugs, it may not have any direct influence on other resource utilization such as ER visits and hospitalization. Thus, it qualifies as an instrument. From this equation, the inverse mills ration was obtained. In the second stage, each healthcare service utilization variables were regressed on the adherence variable, and other covariates plus the inverse mills ratio created in the first stage. 


$$
Y_{i}=\beta_{0}+\beta_{1} x_{i 1}+\beta_{2} x_{i 2}+\beta_{3} x_{i 3}+\beta_{4} x_{i 4}+\beta_{5} x_{i 5}+\beta_{5} x_{i 6}+e_{i}
$$

Where, $i=1, \ldots, n$

$\boldsymbol{Y}=$ Number of ER Visits

$x_{1}=$ Predicted value of MPR

$\boldsymbol{x}_{2}=\mathrm{Gender}$

$x_{3}=$ Age

$x_{4}=(\text { Age })^{2}$

$\boldsymbol{x}_{5}=\log ($ Past year expenditure $)$

$x_{6}=$ Charlson comorbidity index

$Y_{i}=\beta_{0}+\beta_{1} x_{i 1}+\beta_{2} x_{i 2}+\beta_{3} x_{i 3}+\beta_{4} x_{i 4}+\beta_{5} x_{i 5}+\beta_{5} x_{i 6}+e_{i}$

Where, $i=1, \ldots, n$

$\boldsymbol{Y}=$ Hospitalization

$x_{1}=$ Predicted value of MPR

$\boldsymbol{x}_{2}=$ Gender

$x_{3}=$ Age

$x_{4}=(\text { Age })^{2}$

$\boldsymbol{x}_{\mathbf{5}}=\log ($ Past year expenditure $)$

$x_{6}=$ Charlson comorbidity index

$Y_{i}=\beta_{0}+\beta_{1} x_{i 1}+\beta_{2} x_{i 2}+\beta_{3} x_{i 3}+\beta_{4} x_{i 4}+\beta_{5} x_{i 5}+\beta_{5} x_{i 6}+e_{i}$

Where, $i=1, \ldots, n$

$\boldsymbol{Y}=\mathrm{SAB}$ use

$x_{1}=$ Predicted value of MPR 
$\boldsymbol{x}_{\mathbf{2}}=$ Gender

$\boldsymbol{x}_{\mathbf{3}}=$ Age

$\boldsymbol{x}_{\mathbf{4}}=(\text { Age })^{2}$

$\boldsymbol{x}_{\mathbf{5}}=\log ($ Past year expenditure $)$

$\boldsymbol{x}_{\mathbf{6}}=$ Charlson comorbidity index 


\section{Chapter IV: Results}

\subsection{Sample Selection and Sample Characteristics}

Based on the diagnostic codes on the outpatient's claims data, total 89,766 patients were identified to have asthma. After analyzing prescription drugs claims of these patients for the recruiting period (July 2000 to July 2001), 7,941 patients were found to use either LABA or LTRA prescription(s). Prescription drug claims for these patients were further analyzed for six months prior to the first occurrence of either LABA or LTRA prescription and 3.466 patients were found to have no evidence of LABA or LTRA use and also evidence of ICS use.

These patients were categorized as stepped up patients and by analyzing their enrollment records only those patients were selected that were continuously enrolled in a health plan for the entire study period (pre-index and post-index period). Further, patients that had evidence of switching from one add on to another during the post index period were excluded from the study. Patients that were diagnosed with chronic obstructive pulmonary disease (COPD), bronchopulmonary dysplasia and respiratory distress syndrome were also excluded. Finally patients below age 5 were excluded to form the final study sample of 1447 patients (Table 3).

In terms of demographic characteristics (Table 4), the study sample had more females than males with average age of 37(SD 19.17). Majority of them were located in north central $(35.52 \%)$, north east $(25.22 \%)$ and south $(33.31 \%)$ with relatively lower percentage of residents (5.94\%) from the west region. In terms of Charlson's comorbidity scores, values ranged from minimum 0 to maximum 11. Charlson's comorbidity scores were assigned based on the number of comorbid conditions present besides asthma multiplied by weights assigned to each comorbid condition Most number of subjects had a comorbidity score in the range of $0-3$ while about $10 \%$ of the total study population had a comorbidity score higher than 3 .

The cost sharing levels were defined by determining percentage of total cost paid by the patients out of pocket Patients were categorized into four categories.: $0-10 \%, 11$ $20 \%, 21-34 \%$ and $>35 \%$ of total cost paid out of pocket. Patients that paid more than $35 \%$ out of pocket were lesser in number $(3.73 \%)$ while all other categories had close to $30 \%$ patients. 
Table 3 Sample selection criteria

\begin{tabular}{lcc}
\hline Sample Selection Criteria & $\begin{array}{c}\text { Number of } \\
\text { Patients Dropped }\end{array}$ & $\begin{array}{c}\text { Number of Patients } \\
\text { Remaining }\end{array}$ \\
\hline
\end{tabular}

Total number of patients with an asthma diagnosis on a outpatient claim

0

89,766

Evidence of using ICS

65,470

24,296

Evidence of LABA/LTRA in the recruiting period, but no evidence of LABA/LTRA use in the pre-index period

Continuous enrollment in the total study period

No evidence of switching from one addon drug to another add-on drug

No evidence of other respiratory conditions

97 1,547

Patients between age 5 and 65 100 1,447 
Table 4 Sample characteristics

\begin{tabular}{|c|c|}
\hline Variable & Asthma Patients (\% or \$) \\
\hline \multicolumn{2}{|l|}{ Gender (\%) } \\
\hline Male & $582(40.22)$ \\
\hline Female & $865(59.78)$ \\
\hline Total & 1,447 \\
\hline Mean Age (SD) & $37.27(19.17)$ \\
\hline \multicolumn{2}{|l|}{ Geographical Region (\%) } \\
\hline Northeast & $365(25.22)$ \\
\hline North Central & $514(35.52)$ \\
\hline South & $482(33.31)$ \\
\hline West & $86(5.94)$ \\
\hline $\begin{array}{c}\text { Pre-Index Average } \\
\text { Healthcare Expenditure } \\
\text { (SD) }\end{array}$ & $\$ 1,623.51(\$ 3,597.08)$ \\
\hline \multicolumn{2}{|l|}{ Comorbidity Score (\%) } \\
\hline 0 & $682(41.13)$ \\
\hline 1 & $427(29.51)$ \\
\hline 2 & $201(13.89)$ \\
\hline 3 & $78(5.39)$ \\
\hline 4 and above & $59(4.13)$ \\
\hline \multicolumn{2}{|l|}{ Cost Sharing Levels (\%) } \\
\hline $0-10 \%$ & $433(29.94)$ \\
\hline $11-20 \%$ & $485(33.54)$ \\
\hline $21-35 \%$ & $474(32.78)$ \\
\hline $36 \%$ and more & $54(3.73)$ \\
\hline \multicolumn{2}{|l|}{ Plan Type (\%) } \\
\hline Non-Fee-for-Service Plan & $1,125(77.75)$ \\
\hline Fee-for-Service Plan & $322(22.25)$ \\
\hline
\end{tabular}




\subsection{Multivariate Regression Analvsis}

Multivariate regression analysis carried out to analyze relationship between cost sharing levels and combined adherence to ICS+LABA/LTRA. This analysis (Table 5) showed a negative association between cost sharing levels and adherence to the controller regimen among the study population. Multiple dummy variables with different cost sharing levels were used to analyze effect of cost sharing levels $(0-10 \%, 11-20 \%, 21-35 \%$ and $>36 \%$ ) on adherence to the controller drugs.

The $0-10 \%$ cost sharing level was used as reference group and change in the adherence was measured. Results showed that patients having co-pay levels at 11-20\% had a $5 \%$ decrease $(\beta=-0.05153 p=0.006)$ in adherence while patients having $21-35 \%$ co-pay had a $12 \%$ decrease in adherence compared to the patients having $0-10 \%$ co-pay.

Asthma patient that paid more than $36 \%$ cost out of pocket had the lowest rate of adherence $(\beta=-0.1906 \mathrm{p}=<0.001)$ demonstrating overall drop in adherence with increase in co-pay levels. The null hypothesis for this analysis was that the adherence levels would not be affected by changes in the cost sharing. However, since significant drop in adherence with respect to the cost sharing levels was observed, null hypothesis was rejected.

In terms of other demographic characteristics, compared to the patients from south, patients in all other regions (Northeast $-\beta=0.029 p=0.0649$ North Central $\beta=$ $0.0571 \mathrm{p}=0.004$ West $\beta=0.081 \mathrm{p}=0.0027$ ) were found to be more adherent to the ICS regimen. Charlson's co-morbidity score $(\beta=0.004 p=0.346)$ and gender $(\beta=-0.01995 p$ $=0.1207$ ) had a statistically insignificant association with the adherence while pre index health care expenditure had a negative association $(\beta=-0.0051 \mathrm{p}=0.0207)$ Compared to fee for service plans, patients in non fee for service plans were found to have better adherence. $(\beta=-0.0966-p=<0.001)$ The parameter estimate for age variable was negative $(\beta=-0.0061-p=<0.001)$ while the estimate for age square was positive $(\beta=$ $0.00011-\mathrm{p}=<0.001)$ showing a curvilinear relationship with the controller adherence.

Analysis of ICS adherence and cost sharing association before and after index period (Table 6) showed an increased magnitude of negative association in post index period ( $\beta-0.005 \mathrm{p}=<0.001)$. The null hypothesis here was that there would not be any change in controller adherence with respect to the cost sharing levels. However as the analysis showed an increased magnitude of negative association, showing an increased sensitivity to the cost sharing the null hypothesis was rejected 
Table 5 Multivariate regression: association between cost sharing and combined controller (ICS+LABA/ LTRA) adherence

\begin{tabular}{|c|c|c|}
\hline Variable & Parameter Estimate & P-Value \\
\hline \multicolumn{3}{|l|}{ Cost sharing level } \\
\hline \multicolumn{3}{|l|}{$0-10 \%$ (Reference) } \\
\hline $11-20 \%$ & -0.05153 & $0.006^{*}$ \\
\hline $21-35 \%$ & -0.12096 & $<.0001^{*}$ \\
\hline $36 \%$ and more & -0.19069 & $<.0001^{*}$ \\
\hline $\begin{array}{c}\text { Age } \\
\text { Age Square }\end{array}$ & $\begin{array}{c}-0.00661 \\
0.00011483\end{array}$ & $\begin{array}{l}<.0001^{*} \\
<.0001^{*}\end{array}$ \\
\hline \multicolumn{3}{|l|}{ Gender } \\
\hline \multicolumn{2}{|l|}{ Male (Reference) } & 0.1207 \\
\hline \multicolumn{3}{|l|}{ Region } \\
\hline \multicolumn{3}{|l|}{ South (Reference) } \\
\hline Northeast & 0.02956 & 0.0649 \\
\hline North Central & 0.05714 & $0.0004^{*}$ \\
\hline West & 0.08105 & $0.0027^{*}$ \\
\hline $\begin{array}{l}\text { Pre-Index Healthcare } \\
\text { Expenditure }\end{array}$ & -0.0051 & $0.0207^{*}$ \\
\hline $\begin{array}{c}\text { Comorbidity Index } \\
\text { Plan Type } \\
\text { Non Fee-for-Service plan } \\
\text { (Reference) }\end{array}$ & 0.00486 & 0.3467 \\
\hline Fee- for-Service Plan & -0.0966 & $<.0001^{*}$ \\
\hline
\end{tabular}

* Statistically significant at 0.05 alpha

n: 1442 R-Square: 0.47 
Table 6 Multivariate regression: association between cost sharing and steroid adherence in the pre-index and post-index period

\begin{tabular}{|c|c|c|c|c|}
\hline \multirow[b]{2}{*}{ Variable } & \multicolumn{2}{|c|}{ ICS Adherence Pre-index } & \multicolumn{2}{|c|}{ ICS Adherence Post-index } \\
\hline & $\begin{array}{c}\text { Parameter } \\
\text { Estimate }\end{array}$ & P-Value & $\begin{array}{c}\text { Parameter } \\
\text { Estimate }\end{array}$ & P-Value \\
\hline Cost Sharing & -0.00484 & $<.0001^{*}$ & -0.00566 & $<.0001^{*}$ \\
\hline Age & -0.00075245 & 0.634 & -0.00184 & 0.2881 \\
\hline Age Square & 0.00004453 & $0.0488^{*}$ & 0.00006515 & 0.0085 \\
\hline \multicolumn{5}{|l|}{ Gender } \\
\hline \multicolumn{5}{|l|}{ Male (Reference) } \\
\hline Female & -0.0159 & 0.2158 & -0.01704 & 0.2254 \\
\hline \multicolumn{5}{|l|}{ Region } \\
\hline \multicolumn{5}{|l|}{ South (Reference) } \\
\hline Northeast & 0.02487 & 0.1201 & 0.01631 & 0.3514 \\
\hline North Central & 0.05469 & $0.0007^{*}$ & 0.05487 & $0.0018^{*}$ \\
\hline West & 0.08253 & $0.0022^{*}$ & 0.08057 & $0.0064^{*}$ \\
\hline \multicolumn{5}{|l|}{ Pre-Index Healthcare } \\
\hline Expenditure & -0.00586 & $0.0078^{*}$ & -0.0062 & $0.0101^{*}$ \\
\hline Comorbidity Index & 0.004 & 0.4382 & 0.00288 & 0.61 \\
\hline \multicolumn{5}{|l|}{$\begin{array}{c}\text { Plan Type } \\
\text { Non-Fee-for-Service } \\
\text { (Reference) }\end{array}$} \\
\hline Fee- for-Service Plan & -0.08797 & $<.0001^{*}$ & -0.10568 & $<.0001^{*}$ \\
\hline
\end{tabular}

* Statistically significant at 0.05 alpha

ICS $=$ Inhaled Corticosteroids

n: 1442 R-Square: 0.48 


\subsection{Comparison of Regression Co-efficient between ICS $+L A B A$ and $\underline{I C S+L T R A}$}

To compare the change adherence levels with respect to cost sharing between ICS+LABA and ICS+LTRA users, two regression models were built to obtain two different regression coefficients. Both the models included cost sharing as a continuous variable. The total sample had $898(62.0 \%)$ patients that were prescribed ICS+LABA while 549(37.94\%) patients were prescribed ICS+LTRA therapy (Table 7).

In terms of pre-index characteristics, subjects in ICS+LTRA group were less likely to be females and younger in age than the ICS+LABA group. These differences were appropriately controlled in the multivariate regression models.

ICA + LABA cohort produced a slightly lower regression coefficient $(\beta=-0.0042$ $\mathrm{p}=<0.001)$ than the ICS + LTRA cohort $(\beta=-0.005 \mathrm{p}=<0.002)$ demonstrating the difference in adherence levels as a response to co pay level (Table 8). Both the coefficients were tested using Student t-test to find out if the difference between them is statistically significant. The t-test result showed a statistically significant difference between these two values.

The null hypothesis in this case was that there would not be any difference in the cost sensitivity for these two options. However, since there was significant difference in the cost sensitivity between the ICS+LABA and ICS+LTRA sub groups, null hypothesis was rejected.

\subsection{Adherence and Healthcare Resources Utilization}

Among the study population, $140(9.68 \%)$ patients had at least one asthma related ER visit in the post index period while $67(4.6 \%)$ patients had at least one asthma related hospitalization in the post index period (Table 9).

Based on the data from outpatient, inpatient and prescription drug claims, total number of ER visits, days spent in hospital and number of SAB prescriptions used was calculated for each individual patient. About $9 \%$ of the patients in each cohort had at least one ER visit. Close to 4\% patients in ICS+LABA cohort had at least one hospitalization while $5.46 \%$ of patients had at least one hospitalization. SAB use was also similar in two cohorts with average of 2.12 prescriptions in ICS+LABA group and 2.47 prescriptions in ICS+LTRA group. Controller adherence was slightly better (48\% MPR) in ICS+LTRA group compared to the ICS+LABA group (43\% MPR) 
Table 7 Pre-index characteristics for ICS+LABA and ICS+LTRA cohorts

\begin{tabular}{|c|c|c|c|}
\hline Variable & ICS + LABA & ICS+ LTRA & P-Value \\
\hline Gender (\%) & & & $0.002^{\mathrm{a}}$ \\
\hline Male & $328(36.53)$ & $254(46.27)$ & \\
\hline Female & $570(63.47)$ & $295(53.73)$ & \\
\hline Total & 898 & 549 & \\
\hline Mean Age & 42.35 & 28.77 & $<0.001^{\mathrm{b}}$ \\
\hline $\begin{array}{c}\text { Geographical Region } \\
(\%)\end{array}$ & & & $0.3703^{\mathrm{a}}$ \\
\hline Northeast & $219(24.39)$ & $146(26.59)$ & \\
\hline North Central & $315(35.08)$ & $199(36.25)$ & \\
\hline South & $313(34.86)$ & $169(30.78)$ & \\
\hline West & $51(5.68)$ & $35(6.19)$ & \\
\hline $\begin{array}{c}\text { Pre-Index Average } \\
\text { healthcare expenditure }\end{array}$ & $1,706.41$ & $1,487.91$ & $0.2918^{b}$ \\
\hline Comorbidity Score (\%) & & & $0.0407^{\mathrm{a}}$ \\
\hline 0 & $446(49.6)$ & $236(42.9)$ & \\
\hline 1 & $263(29.28)$ & $164(29.8)$ & \\
\hline 2 & $113(12.5)$ & $88(16.02)$ & \\
\hline 3 & $40(4.4)$ & $38(6.9)$ & \\
\hline 4 and above & $36(4.0)$ & $23(4.18)$ & \\
\hline Cost sharing levels (\%) & & & $<0.001^{\mathrm{a}}$ \\
\hline $0-10 \%$ & $254(28.29)$ & $117(21.31)$ & \\
\hline $11-20 \%$ & $356(39.64)$ & $176(32.06)$ & \\
\hline $21-35 \%$ & $257(28.62)$ & $237(43.17)$ & \\
\hline $36 \%$ and more & $31(3.45)$ & $19(3.46)$ & \\
\hline Plan Type (\%) & & & $0.1458^{\mathrm{a}}$ \\
\hline Non-Fee-for-Service Plan & $687(76.5)$ & $438(79.78)$ & \\
\hline Fee-for-Service Plan & $211(23.5)$ & $111(20.22)$ & \\
\hline
\end{tabular}
a. Pearson's Chi-square test
b. Student's t-test
ICS $=$ Inhaled Corticosteroids
LABA = Long-Acting Beta-2 Agonists
LTRA $=$ Leukotrine receptor Antagonist 
Table 8 Multivariate regression: association between cost sharing and LABA/LTRA adherence

\begin{tabular}{|c|c|c|c|c|}
\hline \multirow[b]{2}{*}{ Variable } & \multicolumn{2}{|c|}{$\mathbf{I C S}+\mathbf{L A B A}$} & \multicolumn{2}{|c|}{ ICS + LTRA } \\
\hline & $\begin{array}{l}\text { Parameter } \\
\text { Estimate }\end{array}$ & P-Value & $\begin{array}{c}\text { Parameter } \\
\text { Estimate }\end{array}$ & P-Value \\
\hline Cost sharing & -0.00427 & $<.0001^{*}$ & -0.005 & $0.0002^{*}$ \\
\hline Age & 0.00215 & $<.0001^{*}$ & 0.00103 & 0.1198 \\
\hline \multicolumn{5}{|l|}{ Gender } \\
\hline \multicolumn{5}{|l|}{ Male (Reference) } \\
\hline Female & -0.04687 & 0.0127 & -0.0173 & 0.5145 \\
\hline \multicolumn{5}{|l|}{ Region } \\
\hline \multicolumn{5}{|l|}{ South (Reference) } \\
\hline Northeast & -0.00808 & 0.733 & 0.06513 & 0.0548 \\
\hline North Central & 0.03558 & 0.1256 & 0.05034 & 0.1385 \\
\hline West & 0.10226 & $0.0106^{*}$ & 0.02431 & 0.6636 \\
\hline \multicolumn{5}{|l|}{ Pre-Index Healthcare } \\
\hline Comorbidity Index & 0.00333 & 0.6764 & 0.00854 & 0.3962 \\
\hline \multicolumn{5}{|l|}{ Plan Type } \\
\hline \multicolumn{5}{|c|}{$\begin{array}{l}\text { Non-Fee-for-Service Plan } \\
\text { (Reference) }\end{array}$} \\
\hline Fee- for-Service Plan & -0.09344 & $0.0001^{*}$ & -0.06162 & 0.0923 \\
\hline
\end{tabular}

* Statistically significant at 0.05 alpha ICS = Inhaled Corticosteroids LABA= Long-Acting Beta-2 Agonists LTRA = Leukotrine receptor Antagonist n: 1442 R-Square: 0.35 
Table 9 Unadjusted healthcare utilization for the post-index follow up period

\begin{tabular}{ccc}
\hline Description & ICS+LABA & ICS+LTRA \\
\hline $\begin{array}{c}\text { Patients having at least one ER } \\
\text { visit (\%) }\end{array}$ & $84(9.3)$ & $50(9.1)$ \\
$\begin{array}{c}\text { Patients having at least one } \\
\text { hospitalization (\%) }\end{array}$ & $37(4.12)$ & $30(5.46)$ \\
$\begin{array}{c}\text { Average number of SAB } \\
\text { prescriptions (SD) }\end{array}$ & $2.12(5.05)$ & $2.47(4.31)$ \\
Adherence (SD) & $0.43(0.23)$ & $0.48(0.24)$ \\
\hline
\end{tabular}

ICS $=$ Inhaled Corticosteroids

LABA $=$ Long-Acting Beta-2 Agonists

LTRA $=$ Leukotrine receptor Antagonist 
A multivariate two stage regression model was built to quantify the relationship between adherence and ER visits. Results from the regression model (Table 10) showed an overall drop in number of ER visits with the increase in adherence levels $(\beta=-0.634 p$ $=<0.05$ ). However when analyzed the similar association within ICS+LABA and ICS+LTRA cohorts separately, only ICS+LABA $(\beta=-0.1244 p=0.0075)$ group showed a drop in ER visits with respect to the adherence level (Table 11). Regarding the covariates used in this model only comorbidity index $(\beta=-0.02011 \mathrm{p}=<0.001)$ had a significant association with the ER visits.

Another multivariate two stage regression model was built to quantify the relationship between adherence and hospitalization. Results from the regression model (Table 12) showed no significant relationship between controller adherence and hospital stay $(\beta=-0.1140 \mathrm{p}=0.2286)$. When the same relationship was analyzed separately for $\operatorname{ICS}+\operatorname{LABA}(\beta=-0.08789 p=0.2257)$ and ICS $+\operatorname{LTRA}(\beta=0.1768 p=0.374)$, none of the models yielded significant association between controller adherence and hospital stay (Table 13) Among the other predictors only comorbidity score $(\beta=-0.0408 p=0.0045)$ was found to be associated with the hospital stay.

To analyze the association between SAB use and controller adherence a similar multivariate two stage regression model was built (Table 14). The same relationship was analyzed separately for ICS $+\operatorname{LABA}(\beta=-0.0090 \mathrm{p}=0.9553)$ and ICS $+\mathrm{LTRA}(\beta=-0.0519$ $\mathrm{p}=0.6557)$, none of the models yielded significant association between controller adherence and SAB use (Table 15) This model also did not show any significant association between controller adherence and SAB use $(\beta=0.02498 \mathrm{p}=0.7971)$ and among the other predictors only age $(\beta=-0.02881 \mathrm{p}=0.008)$ and age square $(\beta=0.00046$ $\mathrm{p}=0.0026)$ were significantly associated with the controller adherence.

The null hypotheses for all three health services utilization outcomes expected reduction in the utilization with respect to the controller adherence. However, only in case of ER visits reduction in utilization was observed to be significantly associated with the reduction in utilization and therefore the null hypothesis was rejected only in case of ER visits. In case of hospital stay and SAB use the null hypothesis could not be rejected. 
Table 10 Multivariate two stage regression: association between controller adherence and number of ER visits

\begin{tabular}{|c|c|c|}
\hline Variable & Parameter Estimate & P-Value \\
\hline Adherence & -0.06341 & $0.05^{*}$ \\
\hline Age & 0.000116 & 0.9739 \\
\hline Age Square & -0.00002 & 0.6293 \\
\hline \multicolumn{3}{|l|}{ Gender } \\
\hline \multicolumn{3}{|l|}{ Male (Reference) } \\
\hline Female & -0.00213 & 0.9408 \\
\hline \multicolumn{3}{|l|}{ Region } \\
\hline \multicolumn{3}{|l|}{ South (Reference) } \\
\hline Northeast & -0.01252 & 0.7258 \\
\hline North Central & 0.007575 & 0.8265 \\
\hline West & -0.02653 & 0.6591 \\
\hline $\begin{array}{l}\text { Pre-Index Healthcare } \\
\text { Expenditure }\end{array}$ & -0.00648 & 0.5745 \\
\hline Comorbidity Index & 0.020117 & $<.0001^{*}$ \\
\hline \multicolumn{3}{|l|}{ Plan Type } \\
\hline \multicolumn{3}{|l|}{$\begin{array}{c}\text { Non-Fee-for-Service Plan } \\
\text { (Reference) }\end{array}$} \\
\hline Fee- for-Service Plan & 0.01314 & 0.7173 \\
\hline
\end{tabular}

* Statistically significant at 0.05 alpha

n: 1442 R-Square: 0.42 
Table 11 Multivariate two stage regression: association between controller adherence and ER visits among ICS+LABA and ICS+LTRA cohorts

\begin{tabular}{|c|c|c|c|c|}
\hline \multirow[b]{2}{*}{ Variable } & \multicolumn{2}{|c|}{ ICS + LABA } & \multicolumn{2}{|c|}{ ICS+ LTRA } \\
\hline & $\begin{array}{l}\text { Parameter } \\
\text { Estimate }\end{array}$ & P-Value & $\begin{array}{l}\text { Parameter } \\
\text { Estimate }\end{array}$ & P-Value \\
\hline Adherence & -0.12448 & $0.0075^{*}$ & -0.0198 & 0.6961 \\
\hline Age & 0.00293 & 0.533 & -0.0017 & 0.7919 \\
\hline Age Square & -0.00005245 & 0.4049 & -0.00000444 & 0.964 \\
\hline \multicolumn{5}{|l|}{ Gender } \\
\hline Female & -0.00796 & 0.8152 & 0.00019083 & 0.997 \\
\hline \multicolumn{5}{|l|}{ Region } \\
\hline \multicolumn{5}{|l|}{ South (Reference) } \\
\hline Northeast & 0.01075 & 0.7987 & -0.06388 & 0.326 \\
\hline North Central & 0.06199 & 0.1268 & -0.07464 & 0.2377 \\
\hline West & -0.02247 & 0.7542 & -0.04219 & 0.6935 \\
\hline $\begin{array}{l}\text { Pre-Index Healthcar } \\
\text { Expenditure }\end{array}$ & 0.01075 & 0.4528 & -0.02747 & 0.1601 \\
\hline Comorbidity Index & 0.0182 & $0.0012^{*}$ & 0.02337 & $0.0142^{*}$ \\
\hline \multicolumn{5}{|l|}{ Plan Type } \\
\hline \multicolumn{5}{|l|}{$\begin{array}{l}\text { Non Fee-for-Service Plan } \\
\text { (Reference) }\end{array}$} \\
\hline Fee- for-Service Plan & -0.02303 & 0.5864 & 0.06984 & 0.2982 \\
\hline $\begin{array}{l}\text { * Statistically significan } \\
\text { ICS = Inhaled Corticost } \\
\text { LABA= Long-Acting B } \\
\text { LTRA = Leukotrine rec } \\
\text { n: } 1442 \text { R-Square: } 0.44\end{array}$ & $\begin{array}{l}.05 \text { alpha } \\
\text { s } \\
\text { Agonists } \\
\text { Antagonist }\end{array}$ & & & \\
\hline
\end{tabular}


Table 12 Multivariate two stage regression: association between controller adherence and number of hospital days

\begin{tabular}{|c|c|c|}
\hline Variable & Parameter Estimate & P-Value \\
\hline Adherence & 0.114093 & 0.2286 \\
\hline Age & -0.01037 & 0.317 \\
\hline Age Square & 0.000183 & 0.2175 \\
\hline \multicolumn{3}{|l|}{ Gender } \\
\hline \multicolumn{3}{|l|}{ Male (Reference) } \\
\hline Female & 0.078549 & 0.3493 \\
\hline \multicolumn{3}{|l|}{ Region } \\
\hline \multicolumn{3}{|l|}{ South (Reference) } \\
\hline Northeast & -0.11808 & 0.2579 \\
\hline North Central & -0.17505 & 0.0833 \\
\hline West & -0.07082 & 0.687 \\
\hline \multicolumn{3}{|l|}{ Pre-Index Healthcare } \\
\hline Expenditure & 0.023119 & 0.4929 \\
\hline Comorbidity Index & 0.040898 & $0.0045^{*}$ \\
\hline \multirow{2}{*}{\multicolumn{3}{|c|}{$\begin{array}{c}\text { Plan Type } \\
\text { Non Fee-for-Service Plan } \\
\text { (Reference) }\end{array}$}} \\
\hline & & \\
\hline Fee- For-Service Plan & -0.0396 & 0.7089 \\
\hline
\end{tabular}

* Statistically significant at 0.05 alpha

n: 1442 R-Square: 0.23 
Table 13 Multivariate two stage regression: association between controller adherence and hospital stay among ICS+LABA and ICS+LTRA cohorts

\begin{tabular}{|c|c|c|c|c|}
\hline \multirow[b]{2}{*}{ Variable } & \multicolumn{2}{|c|}{ ICS + LABA } & \multicolumn{2}{|l|}{ ICS+ LTRA } \\
\hline & $\begin{array}{l}\text { Parameter } \\
\text { Estimate }\end{array}$ & P-Value & Parameter Estimate & P-Value \\
\hline Adherence & -0.08789 & 0.2257 & 0.1768 & 0.374 \\
\hline Age & -0.01012 & 0.1679 & -0.02182 & 0.388 \\
\hline Age Square & 0.00014782 & 0.1331 & 0.00045309 & 0.2405 \\
\hline \multicolumn{5}{|l|}{ Gender } \\
\hline \multicolumn{5}{|l|}{ Male (Reference) } \\
\hline Female & 0.00835 & 0.8752 & 0.18954 & 0.3473 \\
\hline \multicolumn{5}{|l|}{ Region } \\
\hline \multicolumn{5}{|l|}{ South (Reference) } \\
\hline Northeast & 0.00672 & 0.9187 & -0.354 & 0.1655 \\
\hline North Central & -0.03332 & 0.5991 & -0.43851 & 0.0772 \\
\hline West & 0.01053 & 0.9251 & -0.2096 & 0.6177 \\
\hline \multicolumn{5}{|l|}{ Pre-Index Healthcare } \\
\hline Comorbidity Index & 0.03108 & $0.0004^{*}$ & 0.05729 & 0.1249 \\
\hline \multicolumn{5}{|l|}{$\begin{array}{c}\text { Plan Type } \\
\text { Non Fee-for-Service } \\
\text { Plan (Reference) }\end{array}$} \\
\hline Fee- for-Service Plan & -0.0151 & 0.8194 & -0.12201 & 0.6431 \\
\hline $\begin{array}{l}* \text { Statistically signific } \\
\text { ICS = Inhaled Cortice } \\
\text { LABA= Long-Acting } \\
\text { LTRA= Leukotrine r } \\
\text { n: } 1442 \text { R-Square: } 0 .\end{array}$ & $\begin{array}{l}\text { nt at } 0.05 \text { alph } \\
\text { teroids } \\
\text { Beta- } 2 \text { Agonist } \\
\text { eptor Antagon }\end{array}$ & & & \\
\hline
\end{tabular}


Table 14 Multivariate two stage regression: association between controller adherence and $\mathrm{SAB}$ refills

\begin{tabular}{|c|c|c|}
\hline Variable & Parameter Estimate & P-Value \\
\hline Adherence & 0.024983 & 0.7971 \\
\hline Age & -0.02881 & $0.0068^{*}$ \\
\hline Age Square & 0.00046 & $0.0026^{*}$ \\
\hline \multicolumn{3}{|l|}{ Gender } \\
\hline \multicolumn{3}{|l|}{ Male (Reference) } \\
\hline Female & -0.06494 & 0.4507 \\
\hline \multicolumn{3}{|l|}{ Region } \\
\hline \multicolumn{3}{|l|}{ South (Reference) } \\
\hline Northeast & -0.17179 & 0.1087 \\
\hline North Central & -0.15794 & 0.1277 \\
\hline West & -0.10106 & 0.5752 \\
\hline \multicolumn{3}{|l|}{ Pre-Index Healthcare } \\
\hline Expenditure & 0.000428 & 0.9901 \\
\hline Comorbidity Index & 0.006535 & 0.6579 \\
\hline \multicolumn{3}{|l|}{ Plan Type } \\
\hline \multicolumn{3}{|l|}{$\begin{array}{c}\text { Non-Fee-for-Service Plan } \\
\text { (Reference) }\end{array}$} \\
\hline Fee- for-Service Plan & 0.020267 & 0.8522 \\
\hline
\end{tabular}

* Statistically significant at 0.05 alpha

n: 1442 R-Square: 0.31 
Table 15 Multivariate two stage regression: association between controller adherence and SAB refills among ICS+LABA and ICS+LTRA cohorts

\begin{tabular}{|c|c|c|c|c|}
\hline \multirow[b]{2}{*}{ Variable } & \multicolumn{2}{|c|}{ ICS + LABA } & \multicolumn{2}{|c|}{ ICS+ LTRA } \\
\hline & $\begin{array}{l}\text { Parameter } \\
\text { Estimate }\end{array}$ & P-Value & $\begin{array}{l}\text { Parameter } \\
\text { Estimate }\end{array}$ & P-Value \\
\hline Adherence & -0.00906 & 0.9553 & -0.05194 & 0.6567 \\
\hline Age & -0.01974 & 0.2275 & -0.0441 & $0.0031^{*}$ \\
\hline Age Square & 0.00033133 & 0.1313 & 0.00075351 & 0.0009 \\
\hline \multicolumn{5}{|l|}{ Gender } \\
\hline \multicolumn{5}{|l|}{ Male (Reference) } \\
\hline Female & -0.11824 & 0.3191 & 0.00011065 & 0.9993 \\
\hline \multicolumn{5}{|l|}{ Region } \\
\hline \multicolumn{5}{|l|}{ South (Reference) } \\
\hline Northeast & -0.25652 & 0.081 & -0.05493 & 0.7141 \\
\hline North Central & -0.10307 & 0.466 & -0.24709 & 0.0903 \\
\hline West & -0.34779 & 0.1644 & 0.27303 & 0.2689 \\
\hline \multicolumn{5}{|l|}{ Pre-Index Healthcare } \\
\hline Comorbidity Index & -0.02794 & 0.5756 & 0.02121 & 0.6379 \\
\hline \multicolumn{5}{|l|}{ Plan Type } \\
\hline \multicolumn{5}{|l|}{$\begin{array}{c}\text { Non Fee-for-Service } \\
\text { plan (Reference) }\end{array}$} \\
\hline Fee- for-Service Plan & -0.05342 & 0.7172 & 0.12092 & 0.4347 \\
\hline $\begin{array}{l}\text { * Statistically significant } \\
\text { ICS = Inhaled Corticoste } \\
\text { LABA= Long-Acting Be } \\
\text { LTRA = Leukotrine rece } \\
\text { n: } 1442 \text { R-Square: } 0.37\end{array}$ & $\begin{array}{l}0.05 \text { alpha } \\
\text { ds } \\
2 \text { Agonists } \\
\text { or Antagonist }\end{array}$ & & & \\
\hline
\end{tabular}




\section{Chapter V: Discussion}

Prescription drug cost sharing has been used as an effective strategy to control prescription drug costs in both privately and publicly funded health plans. Although this strategy has shown reduction in expenditure, the current literature has reported its negative effects such as treatment disruption or discontinuation among chronically ill patients. ${ }^{35}$ Additionally, higher levels of cost sharing can have considerable effects on the use of essential or maintenance medications, and outcomes associated with care. The literature on cost sharing clearly indicates that higher levels of cost sharing result in a larger financial burden to the patient. Currently the majority of studies dealing with the effects of cost sharing focus on homogeneous populations. However, different groups of patients especially those who are chronically ill are affected differently and therefore there is strong need to analyze effects of cost sharing levels on varied subgroups of individuals. ${ }^{35}$ The present study aimed at determining impact of cost sharing levels on adherence to the treatment regimen in case of asthma patients with moderate persistent asthma.

The final sample for this study had more females than males. This has been consistent with the existing literature on asthma drug therapy. Despite the guidelines' preference for ICS + LABA combination as a step up therapy, a significant percentage of asthma patients were found to be on ICS +LTRA. This showed the fact that leukotrine receptor modifiers still have a place in current asthma medication treatment. Other demographics such as age and geographical region were consistent with the asthma literature except for region west which had a very low number of study subjects.

\subsection{Cost Sharing and Adherence}

Results of the study showed an overall negative relationship between cost sharing and adherence to controller drug therapy. It is clear from the results that among the study population, as the cost sharing goes up, adherence levels start dropping significantly. Compared to the patients that had cost sharing at $0-10 \%$ level, as the cost sharing went up adherence dropped gradually at every increase in cost sharing. This effect is more prominent when cost sharing levels are at maximum level. Adherence dropped by $19 \%$ for patients that had cost sharing at 35\% and above (Table1). Analysis also revealed a negative relationship between cost sharing levels and adherence before and after they are stepped up to dual controller therapy. When compared for the cost sensitivity to ICS before and after, patients showed slightly higher sensitivity to ICS after getting stepped to the dual controller therapy. According to the national guidelines patients are stepped up 
to dual controller therapy when their asthma is not controlled by ICS alone. In such patients asthma severity level is higher and therefore there is a greater need to be adherent to the prescribed regimen. However, as the patient has to purchase two medications instead of one, the cost burden is greater. Patients with uncontrolled asthma that were stepped up to the dual controller therapy had a drop in adherence in after they were stepped up to dual controller therapy. Therefore it can be concluded that the increased cost burden plays a significant role in case of these patients.

Comparative analysis between ICS + LABA and ICS + LTRA showed that patients in ICS+LTRA are more sensitive to cost sharing levels than the patients using ICS+LABA. As shown in Table 8 the drop in adherence with respect to cost sharing was greater in case of ICS + LTRA $(\beta=-0.005 p=0.0002)$ compared to ICS + LABA $(\beta=$ $0.00427 \mathrm{p}<0.0001)$ subgroup. One probable reason behind that could be the difference in mechanisms of these two add-on drugs. Both the combinations ICS/LTRA ICS/LABA' have demonstrated improvements in terms of asthma symptoms and exacerbation rates ${ }^{117}$; however, both combinations achieve symptomatic relief through different mechanisms. This difference is mainly attributed to the fact that ICS/LABA combination focuses on improving the lung function whereas; ICS/LTRA's combination focuses on complementary suppression of the airway inflammation. Because of this property LABA are known to produce some symptomatic relief along with the controlling the condition however LTRA does not produce any symptomatic relief along with controlling the inflammation. It could be possible that because of this characteristic patients may value ICS + LABA combination slightly more that the ICS+LTRA combination and therefore they are more sensitive to cost sharing levels in case ICS+LTRA.

In general, despite the recommended guidelines on use of controller drugs, the data showed poor adherence levels with all the controller drugs which were included in this study. The average adherence was 0.48 for the combined controller dug therapy. This is in agreement with the existing literature. Besides the cost sharing, type of insurance plan was also significantly associated with the adherence to controller regimen. Patients in non fee for service plans such as HMO and PPO had better adherence to the all regimens while patients in fee for service plans were less adherent to the prescribed regimen. This underlines the fact that managed care plans are doing better in terms of adherence to the controller drugs. A study done by Crown et al. ${ }^{25}$ also found that the patients in fee for service plan had a lower adherence to the controller drugs.

Further the study also found that geographical region was a significant predictor of the controller drug use. Compared to all other regions, subjects from south were found to be less adherent to the prescribed therapy. Regarding the age of patients, a curvilinear relationship was observed. Inclusion of age and age square variables revealed that 
initially the adherence levels went up as the age was increased and after a certain age adherence levels started dropping with the increase in age. Gender was not found to be associated with the controller adherence. The pre-index healthcare expenditure had a negative correlation with the controller adherence which shows that higher the economic burden could put budget constraints leading to decreased controller adherence.

\subsection{Health Services Utilization Outcomes}

The study further analyzed the association of adherence and asthma related health services utilization such as ER visits, hospital stay and use of SAB. Although health services utilization is not a direct measure of health status or quality of care, increase in utilization of services such as emergency room visits, hospitalization, inpatient and outpatient visits indicate poor health outcomes. Results from this analysis indicated mixed effects regarding the health services utilization. The number of asthma related ER visits were found to be associated with the adherence levels. In general the patients that had higher adherence to the controller regimen had less ER visits after controlling for other factors. Association of higher adherence values to the lower number of ER visits indirectly indicates the better control of asthma. However when the similar analysis was done by separating the study population in to two groups based on the step up therapy they received, only subjects in ICS+LABA had a statistically significant association between the adherence and ER visits. This is also in agreement with the existing literature, which documents better efficacy data for ICS+LABA combination than the ICS + LTRA.

In the case of other health services utilization outcomes, contrary to the study hypothesis, hospital stay and use of SABs were not found to be significantly associated with the overall controller adherence levels as well the adherence levels to the individual add-on drug. Since the total number of hospitalizations in post index was low it might be possible that the study could not capture enough number of hospitalizations to establish a significant association.

In case of SAB use, the controller adherence did not affect the utilization. As controller adherence is expected to be associated with improved control over asthma it was hypothesized that the improved control would lead to decreased symptoms and therefore decreased use of SAB. However the analysis did not show any significant association between controller adherence and SAB use. This can be explained by the possibility that a sub group of patients even though adherent to the controller medication may not be able to administer the controller drugs properly or likely to over treat the

symptoms resulting in concurrent use of SABs. In a study done by Butz et al ${ }^{88}$ found that 
among pediatric asthma patients rate of SAB use actually went up with the use of controller drugs. They also postulated a possibility of sub groups of asthma patients having tendency to consume more drugs.

\subsection{Policy Implications}

This study could impact multiple interest groups namely insurance companies, managed care organizations, government agencies such as Medicaid/Medicare, Health care providers and asthma patients.

Insurance companies/ Managed care designing pharmacy benefit plan: designing the pharmacy benefit plan in terms of various cost sharing levels is a challenging task for insurance companies and government agencies. Since the out of pocket cost plays an important role in the utilization of drugs ${ }^{89}$, defining the various cost sharing levels is crucial to optimize the drug utilization and improve adherence. From the health insurance companies' perspective, well-structured patient cost-sharing policies, ${ }^{90,91}$ have been shown to be more efficient in increasing the cost savings without adversely affecting the health outcomes.

This study will provide helpful information in designing the patient cost sharing policies regarding the asthma controller drugs. The data such as price sensitivity of addon drugs will be helpful in determining the optimum cost sharing levels for the different add on therapies in a pharmacy benefit management policies. The benefits discussed above will apply to state Medicaid programs covering prescription drugs and also to Medicare because of the part D coverage now available to the Medicare beneficiaries.

Patients' perspective: According to a 2002 national estimate, there are 20 million cases of asthma in the US ${ }^{53}$ and this number is rising every year. Since asthma is a chronic condition with no cure available and treatment relying heavily on medication therapy, appropriate utilization of medication is imperative. Number of studies ${ }^{10}$, ${ }^{92}$ recently have demonstrated the reduced morbidity and improved asthma control being associated with the appropriate drug utilization. The current literature also documents considerable divergence ${ }^{10}$ from asthma guidelines in terms of controller drug utilization. This study will be helpful in explaining the role played by cost sharing levels in asthma patients' adherence to controller medication and different add-on options. The results from this study will be helpful in creating awareness amongst asthma patients about importance of controller medication for long term management of the asthma. It is expected that the policy changes based on the study results to be directed towards patient's interests to maximize the adherence to the controller treatment regimens. 
Health care provider's perspective: The current literature provides convincing data on efficacy of both LABA and LTRA combinations through various clinical trials. However, there are a few controversies ${ }^{87}$ regarding the absolute dominance of one combination on other regarding the clinical outcomes. In terms of effectiveness of the combinations the data available from observational studies ${ }^{93-95}$ differ in their conclusions to establish a clear alternative. Therefore in a situation where there is no apparent dominant strategy in terms of efficacy and effectiveness, this study will be useful in documenting information regarding the factors such as adherence of these options and their sensitivity to patient cost-sharing levels. The results from this study will be valuable to physicians and other health care providers in deciding the most appropriate add-on therapy that will improve the outcomes as well as adherence. The information such as knowing the combination therapies to which patients are more sensitive to cost can help understating the additional attention required in monitoring the adherence of the patients on those combinations.

\subsection{Future Research Directions}

For future studies more research should be done to generate more evidence establishing the cost sharing and adherence relationship. One possible way to improve this study would be to add more years of data so that the study subjects could be followed for a longer period of time this may produce more accurate estimates. Adding more years can also increase the sample size significantly allowing using more advanced techniques such as propensity score matching. Since there are new drugs introduced every year, the similar approach can be used by studying more recent data that can provide most recent drugs available in the market. Another limitation of this study was information on race and ethnicity was not available and therefore in future studies it would be interesting to collect information on race ethnicity that could be linked to the insurance claims data to get more accurate and unbiased estimates. The study also did not include data on income level and secondary insurance because of the limited information available in insurance claims database. To overcome these limitations, in future research, it would be of great importance to collect data on variables unavailable in insurance claims, such as race, ethnicity, income, secondary insurance. Combining this information with administrative claims data would create an ideal dataset to study more accurate and unbiased relationship.

The study showed lower adherence levels both pre and post index period, therefore future studies should investigate the role played by adherence levels in increasing asthma severity levels that lead to stepped up therapy. Currently the asthma treatment guidelines are based on the severity levels. If the severity levels are affected by the adherence then more attention needs to be focused in improving the adherence 
because in such cases where patient is stepped up to dual controller therapy as result of lower adherence to prescribed drugs, stepping up may not be an appropriate choice.

Finally, as the scope of this study was limited to patients with asthma only, this framework can be further extended to include more chronic conditions such as hypertension and diabetes where adherence to medication is very important in controlling the condition. Similar approaches in investigating those factors would be helpful in determining how price sensitive people are across a broad range of therapeutic groups which would ultimately help in designing most appropriate drug benefit plan. 


\section{List of References}

(1) Arrow KJ. Uncertainty and the welfare economics of medical care. The American Economic Review 1963;12;53(5):941-73.

(2) Pauly MV. Medicare drug coverage and moral hazard. Health Affairs 2004 January 1;23(1):113-22.

(3) Manning W, Newhouse P, Duan N, Keeler E, Leibowitz A. Health insurance and the demand for medical care: evidence from a randomized experiment. The American Economic Review 1987;77:251-77.

(4) Leibowitz A, Manning WG, Newhouse JP. The demand for prescription drugs as a function of cost-sharing. Social Science and Medicine 1985;21(10):1063-9.

(5) Ellis RP, McGuire TG. Supply-side and demand-side cost sharing in health care. The Journal of Economic Perspectives 1997;7(4):135-51.

(6) Goldman DP, Joyce GF, Zheng Y. Prescription drug cost sharing: associations with medication and medical utilization and spending and health. Journal of the American Medical Association 2007 July 4;298(1):61-9.

(7) Centers for Disease Control and Prevention. Asthma prevention program July 1998.

(8) National Asthma Education and Prevention Program Expert Panel. Guidelines for the diagnosis and management of Asthma. NHLBI produced publications; 1997.

(9) National Heart, Lung and Blood Institute (NHLBI) Clinical practice guidelines, Expert Panel Report 2: guidelines for the diagnosis and management of asthma. 2008

(10) Hong SH, Sanders BH, West D. Inappropriate use of inhaled short acting betaagonists and its association with patient health status. Current Medical Research and Opinion 2006;22:33-40.

(11) Dolan CM, Fraher KE, Bleecker ER et al. Design and baseline characteristics of the epidemiology and natural history of asthma: Outcomes and Treatment Regimens (TENOR) study: a large cohort of patients with severe or difficult-totreat asthma. Annals of Allergy Asthma Immunology 2004 January;92(1):32-9.

(12) Stern L, Berman J, Lumry W et al. Medication compliance and disease exacerbation in patients with asthma: a retrospective study of managed care data. Annals of Allergy Asthma Immunology 2006 September;97(3):402-8. 
(13) Heisler M, Langa KM, Eby EL, Fendrick AM, Kabeto MU, Piette JD. The health effects of restricting prescription medication use because of cost. Med Care 2004 July;42(7):626-34.

(14) Motheral B, Fairman KA. Effect of a three-tier prescription copay on pharmaceutical and other medical utilization. Med Care 2001 December;39(12):1293-304.

(15) Pilote L, Beck C, Richard H, Eisenberg MJ. The effects of cost-sharing on essential drug prescriptions, utilization of medical care and outcomes after acute myocardial infarction in elderly patients. Canadian Medical Association Journal 2002 August 6;167(3):246-52.

(16) Byer B, Myers LB. Psychological correlates of adherence to medication in asthma. Psychology, Health \& Medicine 2000 November;5(4):389-93.

(17) NHLBI/WHO workshop. Global strategy for asthma management and prevention 2006. NIH publication; 2006.

(18) Lieu TA, Lozano P, Finkelstein JA et al. Racial/ethnic variation in asthma status and management practices among children in managed Medicaid. Pediatrics 2002 May 1;109(5):857-65.

(19) Buetow S, Richards D, Mitchell E et al. Attendance for general practitioner asthma care by children with moderate to severe asthma in Auckland, New Zealand. Social Science \& Medicine 2004 November;59(9):1831-42.

(20) Field KS, Briggs DJ. Socio-economic and locational determinants of accessibility and utilization of primary health-care. Health \& Social Care in the Community 2001;9:294-308.

(21) Andersen RM. Revisiting the behavioral model and access to medical care: does it matter? J Health Social Behavior 1995 March;36(1):1-10.

(22) Vignola AM, Bonanno A, Profita $\mathrm{M}$ et al. Effect of age and asthma duration upon elastase and \{alpha\}1-antitrypsin levels in adult asthmatics. European Respiratory Journal 2003 November 1;22(5):795-801.

(23) Mojtabai R, Olfson M. Medication costs, adherence, and health outcomes among Medicare beneficiaries. Health Affairs 2003 July 1;22(4):220-9.

(24) Burney PG. Epidemiology of asthma. Allergy 1993;17-21.

(25) Crown WH, Berndt ER, Baser O et al. Benefit plan design and prescription drug utilization among asthmatics: do patient copayments matter? Front Health Policy Research 2004;7:95-127. 
(26) Mueller KJ, Patil K, Boilesen E. The role of uninsurance and race in healthcare utilization by rural minorities. Health Services Research 1998 August;33(3 Pt 1):597-610.

(27) Agency for Healthcare Research and Quality. Fact sheet: addressing racial and ethnic disparities in health care. 2000 Feb 2. Report No.: AHRQ Publication No. 00-PO41.

(28) Hampson NB. Reduction in patient timing errors using a breath-activated metered dose inhaler. Chest 1994;106(2):462.

(29) Kozma CM, Reeder CE, Schulz RM. Economic, clinical, and humanistic outcomes: a planning model for pharmacoeconomic research. Clinical Therapeutics 1993 November;15(6):1121-32.

(30) Osterberg L, Blaschke T. Adherence to medication. New England Journal of Medicine 2005 August 4;353(5):487-97.

(31) Soumerai SB, Ross-Degnan D. Inadequate prescription-drug coverage for Medicare enrollees -- a call to action. New England Journal of Medicine 1999 March 4;340(9):722-8.

(32) Robert H., Brook JE, William HR. The effect of coinsurance on the health of adults. Results from the RAND Health Insurance Experiment. 1984; Report No.: R-3055-HHS.

(33) Penna P. Three-tier copay systems and consumer-centric care. Journal of Managed Care Pharmacy 2006;6:351-4.

(34) Soumerai SB, Ross-Degnan D, Avorn J, McLaughlin T, Choodnovskiy I. Effects of Medicaid drug-payment limits on admission to hospitals and nursing homes. New England Journal of Medicine 1991 October 10;325(15):1072-7.

(35) Gibson TB, Ozminkowski RJ, Goetzel RZ. The effects of prescription drug cost sharing: a review of the evidence. American Journal of Managed Care 2005 November;11(11):730-40.

(36) Foxman B, Valdez RB, Lohr KN, Goldberg GA, Newhouse JP, Brook RH. The effect of cost sharing on the use of antibiotics in ambulatory care: results from a population-based randomized controlled trial. Journal of Chronic Diseases 1987;40(5):429-37.

(37) Birch S. Relationship between increasing prescription charges and consumption in groups not exempt from charges. The Journal of the Royal College General Practitioners 1986 April;36(285):154-6.

(38) Contoyannis P, Hurley J, Grootendorst P, Jeon SH, Tamblyn R. Estimating the price elasticity of expenditure for prescription drugs in the presence of non- 
linear price schedules: an illustration from Quebec, Canada. Health Economics 2005 September;14(9):909-23.

(39) Gibson TB, McLaughlin CG, Smith DG. A copayment increase for prescription drugs: the long-term and short-term effects on use and expenditures. Inquiry 2005;42(3):293-310.

(40) Artz MB, Hadsall RS, Schondelmeyer SW. Impact of generosity level of outpatient prescription drug coverage on prescription drug events and expenditure among older persons. American Journal of Public Health 2002 August;92(8):1257-63.

(41) Andersson K, Petzold MG, Sonesson C, Lonnroth K, Carlsten A. Do policy changes in the pharmaceutical reimbursement schedule affect drug expenditures? Interrupted time series analysis of cost, volume and cost per volume trends in Sweden 1986-2002. Health Policy 2006 December;79(23):231-43.

(42) Neumann PJ, Sandberg EA, Bell CM, Stone PW, Chapman RH. Are pharmaceuticals cost-effective? A review of the evidence. Health Affairs 2000 March 1;19(2):92-109.

(43) Gage BF, Cardinalli AB, Albers GW, Owens DK. Cost-effectiveness of warfarin and aspirin for prophylaxis of stroke in patients with nonvalvular atrial fibrillation. 1995 December 20;274(23):1839-45.

(44) Schneider T, Fagnani F, Lanoe JL, Hourmant M, Soulillou JP. Economic analysis of an immunosuppressive strategy in renal transplantation. Health Policy 1988;9(1):75-89.

(45) Goldman DP, Joyce GF, Escarce JJ et al. Pharmacy benefits and the use of drugs by the chronically ill. 2004 May 19;291(19):2344-50.

(46) Ellis J, Erickson S, Stevenson J, Bernstein S, Stiles R, Fendrick A. Suboptimal statin adherence and discontinuation in primary and secondary prevention populations. Journal of General Internal Medicine 2004 June 24;19(6):638-45.

(47) Fairman KA, Motheral BR, Henderson RR. Retrospective, long-term follow-up study of the effect of a three-tier prescription drug copayment system on pharmaceutical and other medical utilization and costs. Clinical Therapeutics 2003 December;25(12):3147-61.

(48) Motheral B, Fairman KA. Effect of a three-tier prescription copay on pharmaceutical and other medical utilization. Med Care 2001 December;39(12):1293-304.

(49) Johnson RE, Goodman MJ, Hornbrook MC, Eldredge MB. The effect of increased prescription drug cost-sharing on medical care utilization and 
expenses of elderly health maintenance organization members. Med Care 1997 November;35(11):1119-31.

(50) Christian-Herman J, Emons M, George D. Effects of generic-only drug coverage in a Medicare HMO. Health Affairs 2004 September 29; 455-68.

(51) Tamblyn R, Laprise R, Hanley JA et al. Adverse events associated with prescription drug cost-sharing among poor and elderly persons. 2001 January 24;285(4):421-9.

(52) Mannino DM, Homa DM, Akinbami LJ, Moorman JE, Gwynn C, Redd SC. Surveillance for asthma --- United States, 1980--1999. MMWR; 2002.

(53) Weiss KB An economic evaluation of asthma in the United States. New England Journal of Medicine 2007;(1992):862-6.

(54) Kaiser Family Foundation. Prescription drug trends:fact sheet. The Henry J. Kaiser Family Foundation; 2006.

(55) Weiss KB, Sullivan SD. The health economics of asthma and rhinitis. I. Assessing the economic impact. Journal of Allergy and Clinical Immunology 2001 January; 107(1):3-8.

(56) Centers for Disease Control and Prevention, National Center for Environmental Health. Asthma at-a-glance.Accessed March 29, 2008.

from http://www.cdc.gov/asthma/asthmaAAG.htm

(57) Cited at University of Maryland Medicine, Statistics related to asthma and Allergies. National Institute of Allergy and infectious diseases (NIAID). Nationa 2007.

(58) US Department of Health and Human Services. Healthy People 2010 (Conference ed., Vol II). US Government Printing Office; 2000.

(59) Greening AP, Ind PW, Northfield M, Shaw G. Added salmeterol versus higherdose corticosteroid in asthma patients with symptoms on existing inhaled corticosteroid. The Lancet 1994 July 23;344(8917):219-24.

(60) Pauwels RA, Lofdahl CG, Postma DS et al. Effect of inhaled formoterol and budesonide on exacerbations of Asthma. New England Journal of Medicine 1997 November 13;337(20):1405-11.

(61) Bateman ED, Boushey HA, Bousquet J et al. Can guideline-defined asthma control be achieved?: the gaining optimal asthma control Study. American Journal Respiratory Critical Care Medicine 2004 October 15;170(8):836-44.

(62) Diamant S. Anti-inflammatory mechanisms of leukotriene modulators. Clinical \& Experimental Allergy 1999; 29:1449-53. 
(63) Laviolette M, Malmstrom K, Lu S et al. Montelukast Added to Inhaled Beclomethasone in Treatment of Asthma. American Journal Respiratory Critical Care Medicine 1999 December 1;160(6):1862-8.

(64) Malmstrom K, Rodriguez-Gomez G, Guerra J et al. Oral Montelukast, Inhaled Beclomethasone, and Placebo for Chronic Asthma: A Randomized, Controlled Trial. Annals of Internal Medicine 1999 March 16;130(6):487-95.

(65) Price DB, Hernandez D, Magyar P et al. Randomised controlled trial of montelukast plus inhaled budesonide versus double dose inhaled budesonide in adult patients with asthma. Thorax 2003 March 1;58(3):211-6.

(66) Vaquerizo MJ, Casan P, Castillo J et al. Effect of montelukast added to inhaled budesonide on control of mild to moderate asthma. Thorax 2003 March 1;58(3):204-10.

(67) Busse W, Nelson H, Wolfe J, Kalberg C, Yancey SW, Rickard KA. Comparison of inhaled salmeterol and oral zafirlukast in patients with asthma. The Journal of Allergy and Clinical Immunology 1999 June 1;103(6):1075-80.

(68) Robinson DS, Campbell D, Addition of leukotriene antagonists to therapy in chronic persistent asthma: a randomised double-blind placebo-controlled trial. The Lancet 2001 June 23;357(9273):2007-11.

(69) Fish JE, Israel E, Murray JJ et al. Salmeterol powder provides significantly better benefit than Montelukast in asthmatic patients receiving concomitant inhaled corticosteroid therapy. Chest 2001 August 1;120(2):423-30.

(70) Nelson HS, Busse WW, Kerwin E et al. Fluticasone propionate/salmeterol combination provides more effective asthma control than low-dose inhaled corticosteroid plus montelukast. Journal of Allergy and Clinical Immunology 2000 December;106(6):1088-95.

(71) Barnes PJ, Jonsson B, Klim JB. The costs of asthma. European Respiratory Journal 1996 April 1;9(4):636-42.

(72) Bauman LJ, Wright E, Leickly FE et al. Relationship of adherence to pediatric asthma morbidity among inner-city children. Pediatrics 2002 July 1;110(1):e6.

(73) Finkelstein JA, Lozano P, Farber HJ, Miroshnik I, Lieu TA. Underuse of controller medications among medicaid-insured children with asthma. Archives of Pediatric Adolescents Medicine 2002 June 1;156(6):562-7.

(74) Sherman J, Patel P, Hutson A, Chesrown S, Hendeles L. Adherence to oral montelukast and inhaled fluticasone in children with persistent asthma. Pharmacotherapy 2001 December;21(12):1464-7. 
(75) Jatulis DE, Meng YY, Elashoff RM et al. Preventive pharmacologic therapy among asthmatics: five years after publication of guidelines. Annals Allergy Asthma Immunology 1998 July;81(1):82-8.

(76) Legorreta AP, Christian-Herman J, O'Connor RD, Hasan MM, Evans R, Leung KM. Compliance with national asthma management guidelines and specialty care: a health maintenance organization experience. Archives of Internal Medicine 1998 March 9;158(5):457-64.

(77) Brooks CM, Richards JM, Kohler CL et al. Assessing adherence to asthma medication and inhaler regimens: a psychometric analysis of adult self-report scales. Med Care 1994 March;32(3):298-307.

(78) Steiner JF, Prochazka AV. The assessment of refill compliance using pharmacy records: methods, validity, and applications. Journal of Clinical Epidemiology 1997 January;50(1):105-16.

(79) Tamblyn R, Lavoie G, Petrella L, Monette J. The use of prescription claims databases in pharmacoepidemiological research: The accuracy and comprehensiveness of the prescription claims database in Qubec. Journal of Clinical Epidemiology 1995 August;48(8):999-1009.

(80) Hamilton RA, Briceland LL. Use of prescription-refill records to assess patient compliance. American Journal of Hospital Pharmacy 1992 July;49(7):1691-6.

(81) Hess LM, Raebel MA, Conner DA, Malone DC. Measurement of adherence in pharmacy administrative databases: a proposal for standard definitions and preferred measures. Annals of Pharmacotherapy 2006 July 1;40(7):1280-8.

(82) Sclar DA, Chin A, Skaer TL, Okamoto MP, Nakahiro RK, Gill MA. Effect of health education in promoting prescription refill compliance among patients with hypertension. Clinical Therapeutics 1991 July;13(4):489-95.

(83) Sikka R, Xia F, Aubert RE. Estimating medication persistency using administrative claims data. American Journal of Managed Care 2005 July; 11(7):449-57.

(84) Ungar WJ, Kozyrskyj A, Paterson M, Ahmad F. Effect of cost-sharing on use of asthma medication in children. Archives of Pediatric Adolescent Medicine 2008 February 1;162(2):104-10.

(85) D'Hoore W, Bouckaert A, Tilquin C. Practical considerations on the use of the Charlson comorbidity index with administrative data bases. Journal of Clinical Epidemiology 1996 December;49(12):1429-33.

(86) Charlson ME, Pompei P, Ales KL, MacKenzie CR. A new method of classifying prognostic comorbidity in longitudinal studies: development and validation. Journal of Chronic Diseases 1987;40(5):373-83. 
(87) Diamant Z, van der Molen T. Treating asthma: is there a place for leukotriene receptor antagonists? Respiratory Medicine 2005 June;99(6):655-62.

(88) Butz AM, Tsoukleris M, Donithan M et al. Patterns of inhaled antiinflammatory medication use in young underserved children with asthma. Pediatrics 2006 December 1;118(6):2504-13.

(89) Goldman DP, Joyce GF, Zheng Y. Prescription drug cost sharing: associations with medication and medical utilization and spending and health. 2007 July 4;298(1):61-9.

(90) Marshall JK, Grootendorst PV, O'Brien BJ, Dolovich LR, Holbrook AM, Levy AR. Impact of reference-based pricing for histamine-2 receptor antagonists and restricted access for proton pump inhibitors in British Columbia. Canadian Medical Association Journal 2002 June 25;166(13):1655-62.

(91) Grootendorst PV, Dolovich LR, O'Brien BJ, Holbrook AM, Levy AR. Impact of reference-based pricing of nitrates on the use and costs of anti-anginal drugs. Canadian Medical Association Journal 2001 October 16;165(8):1011-9.

(92) Anis AH, Lynd LD, Wang XH et al. Double trouble: impact of inappropriate use of asthma medication on the use of health care resources. Canadian Medical Association Journal 2001 March 6;164(5):625-31.

(93) Stempel DA, O'Donnell JC, Meyer JW. Inhaled corticosteroids plus salmeterol or montelukast: Effects on resource utilization and costs. Journal of Allergy and Clinical Immunology 2002 March;109(3):433-9.

(94) Ramey FC, Bukstein D, Luskin A, Sajjan SG, Markson LE. Administrative claims analysis of asthma-related health care utilization for patients who received inhaled corticosteroids with either montelukast or salmeterol as combination therapy. Journal of Managed Care Pharmacy 2006 May;12(4):310-21.

(95) O'Connor RD, O'Donnell JC, Pinto LA, Wiener DJ, Legorreta AP. Two-year retrospective economic evaluation of three dual-controller therapies used in the treatment of asthma. Chest 2002 April 1;121(4):1028-35. 


\section{Appendix: Data License Agreement}

\section{THOMSON REUTERS}

777 East Eisenhower Parkway $\quad+\quad+17349133000$
Ann Arbor, Ml 48108

June 16, 2008

Dr. Song Hee Hong

Associate Professor

University of Tennessee Health Science Center

847 Monroe, Suite 226

Memphis, TN 38163

Re: MarketScan Dissertation Support Program and Ph.D., candidate Varun Vaidya

Dear Dr. Hong:

We are pleased to deliver the 2000 and 2001 Commercial Claims \& Encounters (CCAE) and Benefit Plan Design (BPD) databases. The CCAE database contains calendar year incurred claims with at least 6 months of run-off. The BPD database links plan design information to a subset of the enrollees found in the claims databases.

Please note that data and documentation are shipped separately in order to better protect the person-level data in the databases. Both packages are shipped simultaneously and addressed identically.

The following files are included in the Commercial Claims and Encounters Database:

- Inpatient Admissions-Summarizes information about a hospital admission

- Inpatient Services-Contains services rendered during an inpatient stay

- Outpatient Claims/Encounters-Contains services rendered in a doctor's office, hospital outpatient facility, or other outpatient facility

- Outpatient Prescription Drugs (available for a subset of the covered lives)—Contains outpatient prescription drug claims

- Populations-Counts of covered populations by cohorts (supported at the state level of geographic specificity)

- Summary Enrollment (available for a subset of the covered lives)_Provides a single record for each period of continuous enrollment for each covered life, showing enrollment start and end dates and most prevalent demographic and plan information

- Transaction Enrollment (available for a subset of the covered lives)_-Provides a single record per period of continuous enrollment for each covered life, showing detailed plan and demographic changes. 
Dr. Song Hee Hong

May 19, 2008

Page 2

The enrollment files are cumulative and encompass the 2000 and 2001 data years. One summary and one transaction file have been provided.

The files are linkable via a unique patient identifier or enrollee identifier (whichever is applicable) across files and across the years of data. Patients who have joined or left the employer and plan supplying the claims will not have data for the entire time period.

With the data, we have provided a description of deliverables, MarketScan Database User's Guide and Data Dictionary, data quality reports, and media information. All data are delivered in SAS transport files on CD-ROM.

\section{License Term}

The license term will end either upon (i) completion of Varun Vaidya's dissertation and submission of one copy to Thomson Healthcare Inc. Senior Manager, Contracts Administration or (ii) termination in accordance with the contract provisions or (iii) five (5) years from the effective date of this agreement.

Please call me at (805) 681-5855 any questions you might have.

Sincerely,

Nay Mula \&

Kay Miller

Senior Research Manager

Thomson Reuters

5425 Hollister Avenue, Suite 140

Santa Barbara, CA 93111-2348

Kay.Miller (a) thomsonreuters.com

www thomsonreuters.com

Enclosures 


\section{Vita}

Varun Vaidya was born in India on November 27, 1980. He finished his bachelor's degree in pharmaceutical sciences in 2002. After receiving his degree, he worked with Dr. M.S. Bhatia and Dr. S.L Bodhankar on projects in medicinal chemistry and pharmacology from year 2002-2004. In fall 2004 he was accepted at the University of Tennessee as a graduate student in the Ph.D. program (Major: Health Outcomes and Policy Research). 